Spring 4-25-2020

\title{
Supporting The Role And Transition To Motherhood Through The Occupation Of Feeding
}

\author{
BethAnne N. Vidmar \\ University of St. Augustine for Health Sciences \\ DOI: https://doi.org/10.46409/sr.QXBM6474
}

Follow this and additional works at: https://soar.usa.edu/capstones

Part of the Maternal and Child Health Commons, Occupational Therapy Commons, Public Health Education and Promotion Commons, and the Women's Health Commons

\section{Recommended Citation}

Vidmar, B. N. (2020). Supporting The Role And Transition To Motherhood Through The Occupation Of Feeding. [Doctoral project, University of St Augustine for Health Sciences]. SOAR @ USA: Student Capstone Projects Collection. https://doi.org/10.46409/sr.QXBM6474

This Capstone is brought to you for free and open access by the Student Research at SOAR @ USA. It has been accepted for inclusion in Student Capstone Projects by an authorized administrator of SOAR @ USA. For more information, please contact soar@usa.edu, erobinson@usa.edu. 
SUPPORTING THE ROLE AND TRANSITION TO MOTHERHOOD THROUGH THE OCCUPATION OF FEEDING

by

BethAnne N. Vidmar

A Capstone Project Presented in Partial Fulfillment of the Requirements for the Degree of DOCTOR OF OCCUPATIONAL THERAPY

University of St. Augustine for Health Sciences

April 2020 
SUPPORTING THE ROLE AND TRANSITION TO MOTHERHOOD THROUGH

THE OCCUPATION OF FEEDING

by

BethAnne N. Vidmar

has been approved

April 2020

APPROVED:

Susan MacDermott, OTD, OTR/L, Doctoral Coordinator

Becki Cohill OTD OTR/L, Doctoral Coordinator

Erin Schwier, EdD, OTD, OTR/L, Program Director

ACCEPTED AND SIGNED:

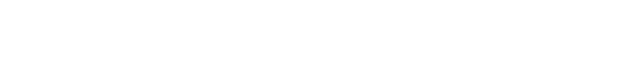

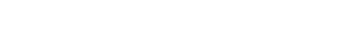

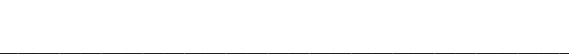

Susan MacDermott, OTD, OTR/L, Doctoral Coordinator

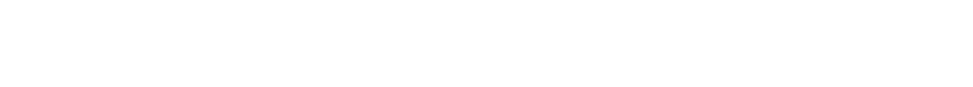

Becki Cohill OTD OTR/L, Doctoral Coordinator

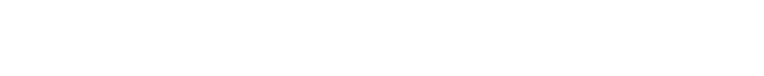

Erin Schwier, EdD, OTD, OTR/L, Program Director 
Table of Contents

Chapter I. Introduction....................................................

Background........................................................ 5

Statement of the Problem................................................ 9

Purpose Statement.................................................. 9

Rationale for Proposed Project...................................... 10

Significance of the Proposed Project.................................... 12

Preliminary Project Objectives......................................... 12

Definition of Terms............................................... 13

Assumptions........................................................ 14

Limitations ..................................................... 14

Delimitations..................................................... 15

Chapter II. Literature Review............................................ 15

Occupational Therapy’s Current Role in Infant Feeding and Peri and Postnatal

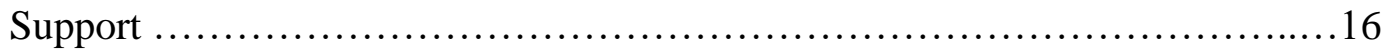

Barriers to Breastfeeding............................................ 16

The Psychosocial Impact on Women During the Transition to Motherhood.......17

Chapter III. Project Description............................................ 19

Project Description................................................ 19

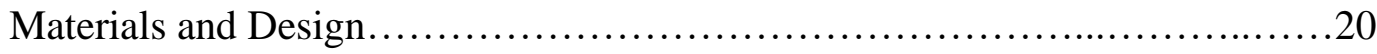

Participants...................................................... 20

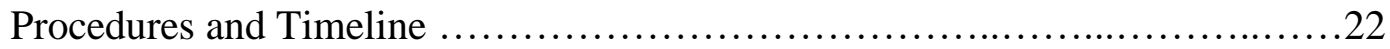


Chapter IV. Data Analysis and Results...........................................23

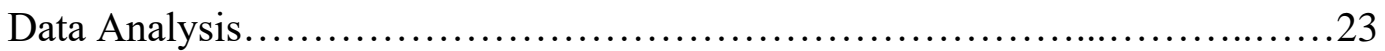

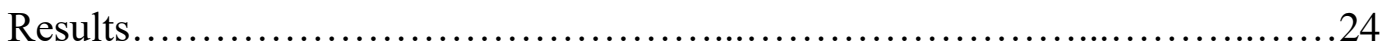

Chapter V. Discussion and Conclusion ................................................ 38

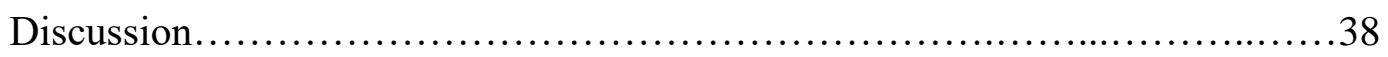

Limitations................................................................ 40

Implications for Occupational Therapy....................................41

Conclusion................................................................... 42

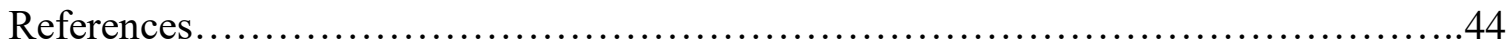

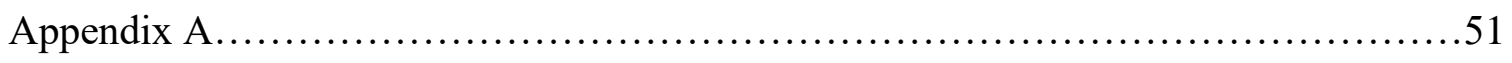

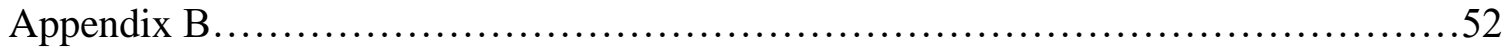

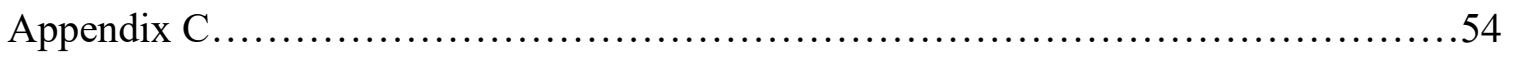

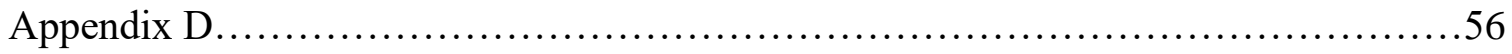

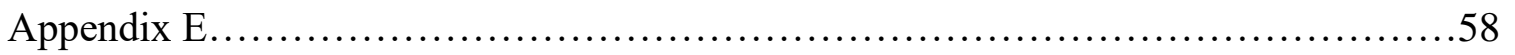

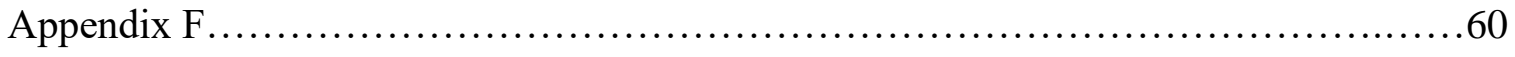

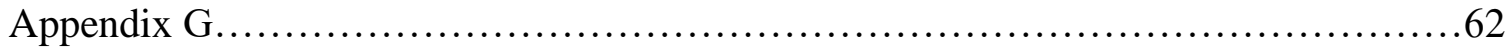

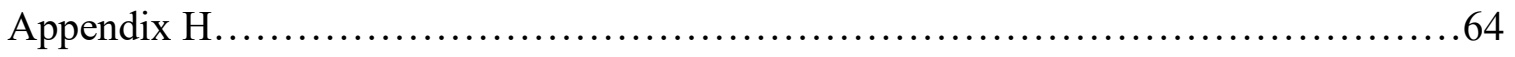

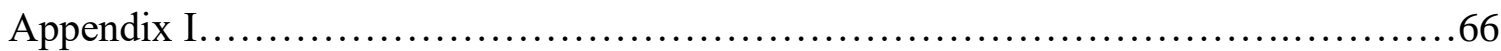

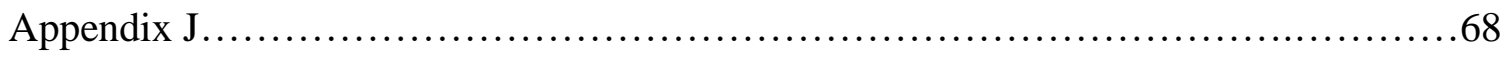




\section{Supporting the Role and Transition to Motherhood through the Occupation of Feeding}

\section{Background}

The World Health Organization (WHO; 2018), states that breastfeeding is the "normal way" to feed infants and that "virtually all mothers can breastfeed" (p. 2). The American Academy of Pediatrics (AAP; 2018) recommends breastfeeding in order to protect the baby against a variety of diseases and conditions throughout their entire lifespan. The AAP (2018) also reports evidence on maternal health benefits including decreased risk of breast and ovarian cancer and osteoporosis. The AAP (2018) suggests that for the first six months of an infant's life, a mother should exclusively breastfeed and then continue for at least a year or more. In the United States approximately $20 \%$ of women stop breastfeeding within one month (Froehlich et al., 2015). Evidence presents that the clear choice is to breastfeed, yet some women choose not to or are unable to.

There are an estimated $15 \%$ of first-time mothers in the United States who are not able to produce enough breast milk to exclusively breastfeed (Hurst, 2007). Conditions that lead to lactation failure include breast and hormonal abnormalities such as, “insufficient mammary glandular tissue, postpartum hemorrhage with Sheehan syndrome, theca lutein cyst, polycystic ovarian syndrome, and some breast surgeries have been implicated as possible causes of lactation failure" (Hurst, 2007, p. 590). "Any condition in the mother that results in incomplete breast emptying (i.e., improper latch on, timed/scheduled feedings, overuse of pacifiers, the unnecessary use of supplements); and some maternal medications (i.e., pseudoephedrine, progestin-only and/or estrogen containing birth control methods)," can also lead to secondary failure of lactation (Hurst, 
2007, p. 590). Secondary conditions to lactation failure include any condition in which the infant has insufficient suck including prematurity, congenital heart defects, ankyloglossia (tongue-tie), and palatal abnormalities (Hurst, 2007). The duration of breastfeeding is influenced by various demographic, physical, social, and psychological variables (Thulier and Mercer, 2009). There are many individual barriers to breastfeeding initiation including: work-related issues, support, feelings of embarrassment, pain, physical problems, personal preferences, and medical issues (Ahluwalia, Morrow, \& Hsia, 2005).

Most women in the United States do not have a follow-up appointment until 6 weeks postpartum and this is typically the only postpartum appointment they will have. Even then, attendance is low, and the obstetrician may not necessarily address maternal concerns regarding breastfeeding (Tully, Stuebe, \& Verbiest, 2017). It is crucial for a physician to ask questions about how a mother is feeling and sleeping, how her moods are, and whether she is experiencing anxiety in order to ensure open communication between mother and health professional about maternal mental health (Kurtz, Levine, \& Safyer, 2017). Stone and Kokanovic (2016) found that women currently feel "uncared for" during early maternity and that health care providers should be treating a mother and her infant together as a unit. The initial phase of breastfeeding is crucial to a woman's milk supply and duration of breastfeeding because so many women experience early breastfeeding difficulties or negative breastfeeding experiences (Palmér \& Jutengren, 2019). A newborn follow-up appointment, usually 3 to 5 days postpartum, and a second visit at 2 weeks are "critical to evaluate the onset of breastfeeding, monitor infant weight 
gain, discuss infant feeding cues, and provide ongoing support to the mother" (Neifert \& Bunik, 2013, p. 115).

Society conveys to women that they are naturally born with the skills needed to begin motherhood (Larson, 2000). This societal belief, with the added pressure of a strong cultural and healthcare driven promotion of breastfeeding, can often contribute to a narrative that makes women feel shame when finding breastfeeding difficult, impossible, or simply stigmatized (Pearson, 2019). It is known that "some women can't or do not wish to breastfeed. Constantly admonishing [women] that they are depriving their babies of important advantages [...] leads to needless feelings of guilt and shame and can potentially exacerbate postpartum depression" (Tuteur, 2019, p.1).

Occupational therapists play a role in specific occupations including, feeding, eating, and swallowing across the lifespan (Boop \& Smith, 2017). An occupational therapist's unique perspective of addressing and evaluating these occupations create an opportunity to address a patient in a holistic way, taking in to account the cultural, environmental, physiological, and psychosocial factors that may interfere with their success (Boop \& Smith, 2017). The Occupational Therapy Practice Framework: Domain and Process (AOTA, 2014) lists breastfeeding as an activity under sleep participation. Infant feeding can also be associated with feeding under Activities of Daily Living (ADLs) as well as health management and maintenance and child rearing under Instrumental Activities of Daily Living (IADLs; AOTA, 2014). Meedya, Fahy, and Kable (2010) describe factors that are positively associated with the length of time women breastfeed including a women's breastfeeding self-efficacy, social support, and her breastfeeding intention. These factors are adaptable and could be addressed in an 
occupational therapy session as feeding, breastfeeding, and child rearing are directly listed as areas within the scope of practice of occupational therapists (AOTA, 2014).

Occupational therapists are equipped to perform activity analysis, adapt and plan tasks, promote skills, establish support, restore and modify schedules, and educate yet, occupational therapy is currently focused on breastfeeding in a physical sense, addressing a baby's ability to latch, suck, and swallow (AOTA, 2014; Boop \& Smith, 2017). Healthy People 2020 is calling for increased rates of exclusive breastfeeding in the United States, due to benefits of breastfeeding for the health of both infants and women (U.S. Department of Health and Human Services, 2010). Occupational therapists are equipped to aide individuals, organizations, and populations in creating routines and habits that support continued breastfeeding while still addressing environmental and contextual barriers that women face. Occupational therapists need to become involved in emerging practice opportunities as consultants to increase and support breastfeeding promotion (Pitonyak, 2014).

Outside of a physical scope, new mothers may not be prepared to or are unable to structure their lives around the needs of feeding an infant (Froehlich et al., 2015). Froehlich et al. (2015), discovered that mothers who were breastfeeding found daily routines to be extremely hard or non-existent. One mother reported, "Breastfeeding consumes my life, all day, all night - I feel like I have no time for much else" (Froehlich et al., 2015, p. 437). Infants tend to drive the routines of their mothers, and new mothers need help in developing a more predictable daily routine (Horne, Corr, and Earle, 2005).

Occupational therapists can change perspectives of breastfeeding to benefit the population of new mothers by applying their unique perspective and knowledge of 
routines and role transitions associated with the occupation of breastfeeding and help enhance the psychosocial and occupational lives of mothers. Approximately $80 \%$ of women begin breastfeeding but need more community support to overcome the challenges of breastfeeding when they are in the hospital, at home, or at their workplace (CDC, 2016). The promotion of self-advocacy skills to women who are struggling with breastfeeding and feeding their infant will encourage women to seek help earlier in order to enhance their occupational balance in transitioning into the role of motherhood.

\section{Statement of the Problem}

The daily routines of mothers, specifically concerning feeding their infants and the role transition to motherhood, needs to be better supported and understood in order to recognize how the current promotion of breastfeeding may be impacting the psychosocial and occupational lives of mothers feeding their infants. The current professional lactation community promotes breastfeeding with a focus on a directive skilled-based approach, without addressing the occupational lives of mothers (Palmér \& Jutengren, 2019). Occupational therapists are uniquely suited to address the roles, routines, rituals, and habits of new mothers in order to promote and incorporate breastfeeding into their daily lives. Furthermore, they are equipped to perform activity analysis on feeding, adapt and plan feeding tasks, promote self-advocacy skills, establish social support, restore and modify schedules, and address infant feeding/swallowing education. Occupational therapists must promote change in the approach to education on breastfeeding in order to ensure the occupational and psychosocial needs of mothers are being met in order to warrant the best breastfeeding outcomes.

\section{Purpose Statement}


This capstone will assess and explore the occupational needs of mothers who are feeding their infants in a variety of ways. Based on these needs, a program will be created to enhance the role of occupational therapy in supporting the occupation of feeding, including breastfeeding, in order to promote self-advocacy skills in mothers and support their psychosocial and occupational lives through enhancing their roles, routines, rituals, and habits.

\section{Rationale for Proposed Project}

Occupational balance can be defined as a "subjective state of harmony or congruence across a person's occupations" (Anaby, Backman, \& Jarus, 2010, p. 281). Mothers who reported finding occupational balance in their lives before having a child, reported a period of time where they experienced occupational disruption before being able to fully adapt to the role as a mother (Horne et al., 2005). Occupational balance is often interrupted in the transition to motherhood, and this transition has been identified as matrescence (Sacks, 2017).

When a woman gives birth, it is assumed that her entire life changes and much of her focus and energy shifts to ensuring that the baby survives (Froehlich et al., 2015). Body morphing and hormone changes drastically alter the mind and body of a woman who has just had a baby; much like the significant transformations a body experiences through adolescence (Sacks, 2017). A mother will feel a pull of having to care and nurture a child, which is interrupted by a push to include other crucial occupations (Sacks, 2017). Factors including a lack of maternal confidence and knowledge, lack of time and place to pump or nurse, attitudes towards breastfeeding, and a lack of support for new mothers make it even harder on women going through a complex role change 
(Froehlich et al., 2015). This is the conflict between occupational balance and occupational imbalance that often makes breastfeeding difficult and warrants the need for the development of greater support to new mothers (Froehlich et al., 2015). According to the "violated expectations framework," women's expectations about their maternal role and how having a child might affect their lives are often not met (Kalmuss, Davidson, and Cushman, 1992). These unmet expectations then affected the women's ability to adjust to motherhood (Kalmuss, et al.,1992). According to Wilkins (2006), when asked about motherhood, a theme of women concerned about "doing it right" emerged. New mothers need to quickly be able to develop skills and coping strategies in order to adjust to their new life role (Horne, et al., 2005).

The transition to motherhood is understood as difficult and life changing. Froehlich (2015) suggested that better examining women's roles and routines around breastfeeding may lead to women's improved ability to breastfeed or to extend the duration of breastfeeding. As health professionals, occupational therapists should continue to promote breastfeeding alongside doctors, lactation consultants, nurses, and researchers. Occupational therapists should add their expertise of being client-centered, and knowledge of role transitions, to promote the skills of self-advocacy for women struggling with, choosing not to or unable to breastfeed, and women who are seeking resources for further help in breastfeeding. This capstone proposes a needs assessment of women who are feeding their infants in various forms, in order to discover the impacts that the promotion of breastfeeding might have on the psychosocial and occupational lives of these women. This needs assessment can then be translated into the development of better support and information for expecting and breastfeeding mothers. 


\section{Significance of the Proposed Project}

Determination of the psychosocial and occupational needs of this population can serve to help further educate and involve health professionals in not only educating mothers about breastfeeding, but also providing continued support in feeding and role transitioning. Clinicians will be able deliver the best quality and client-centered care when there are continuing education opportunities about how to best support lactation and breastfeeding as well as other means of feeding. While breastfeeding is being promoted in health care, many institutions do not support and facilitate mothers to be able to breastfeed or pump. Public awareness in the community needs to be strengthened and expanded so that mothers can be best supported in the occupation of breastfeeding in or out of the home. Community backing is needed to support women feeding their babies using various methods in order to reduce postpartum depression, a shame narrative, and difficulty in the transition to motherhood (Hinde, 2016).

\section{Preliminary Project Objectives}

- $\quad$ Summarize the current role of occupational therapy in breastfeeding.

- $\quad$ Observe breastfeeding classes, parenting classes, and support groups to assess mothers' current concerns, supports, and barriers with feeding.

- Interview mothers within community and structured programs who are feeding their infants and asses their psychosocial and occupational needs.

- Explore mothers' perceptions of the current breastfeeding support they are receiving or that they perceive to be available. 
- Interview lactation consultants, nurses, occupational therapists, and other allied health professionals working with breastfeeding to better understand their role and perception of mothers' needs.

- Identify psychosocial and occupational barriers effecting women's choices in feeding options for their infant through surveys and interviews.

- Identify opportunities for occupational therapists to become more involved in the occupation of breastfeeding.

- $\quad$ Educate mothers on occupational balance, role transition, and routine development in order to support their infant feeding.

\section{Definition of Terms}

- Activities of Daily Living (ADLs) include any activity meant to take care of one's body. They are central to a person's basic health and wellness (American Occupational Therapy Association, 2014).

- Instrumental Activities of Daily Living (IADLs) incorporate activities that support occupations within one's home and in the community. They are viewed as more complex exchanges than what is required in ADLs and often involve others (American Occupational Therapy Association, 2014).

- Co-occupation is defined as an occupation shared with at least one other person. It is a synchronous experience between individuals involved that in turn creates shared occupational experiences. In this paper co-occupation will refer to occupations shared by the mother and her infant that promote the development of the family (Pizur-Barnekow, 2010; Price \& Miner, 2009). 
- Infant feeding is a term used to be inclusive of all forms of feeding incorporating breastfeeding and all forms of complementary or replacement feeding (WHO, 2018).

\section{Assumptions}

This project makes the assumption that the role and transition to motherhood is difficult for some mothers and that motherhood presents barriers to occupations (Froehlich et al., 2015; Horne, Corr, \& Earle, 2005). It is assumed that the women being interviewed in this project are able to be transparent of their personal experiences as mothers and that this population of women is representative of most mothers. Moreover, it is assumed that the current lactation support being given to mothers is lacking and that that these health professionals will be open to further education and training in occupations related to motherhood, specifically feeding.

\section{Limitations}

Surveys will be conducted using a sample of convenience, therefore a limitation to this project will be that the needs of these mothers can only be suggested as similar to experiences of the general population of mothers. The surveys and interviews will be limited to the women who have access to the healthcare provided at Cottage Hospital in the Lompoc, Goleta, and Santa Barbara areas and Santa Barbara County community programs. The study may be limited by the women participating due to specific diagnosis, traumatic births, and the women's personal struggles. Furthermore, a limitation may be that women do not feel comfortable with speaking to or having health professionals in their home and therefore choose not to participate. Options will be 
provided to enable mothers to participate through written survey, online survey, phone interview, or in-person interview.

\section{Delimitations}

A major delimitation to this project will be the choice to only look at mothers' experiences, excluding any partners. This project will also be open to currently pregnant women and mothers with a $0-12$-month-old, with no exclusions to specific diagnosis or experiences. Each mother's experience will be varied and impact their ability to feed differently based on their infant's needs. This study will look at specific components of occupational performance. Therefore, occupational performance will only be related to areas of feeding and occupations associated with motherhood and not related to overall participation in varied occupations of life. The student intends to educate health professionals and staff on addressing occupational and psychosocial needs that occur during motherhood however carryover of practice will be the responsibility of the health professionals and organizations educated.

\section{Chapter II: Literature Review}

This chapter summarizes the current literature into supported themes. The emerging evidence is categorized into the following: Occupational therapy's current role in infant feeding and peri and postnatal support, barriers to breastfeeding, and the psychosocial impact on women during the transition to motherhood. A gap has been identified in the literature regarding addressing breastfeeding disparities through maternal knowledge and self-efficacy in infant feeding (Alghamdi, Horodynski, \& Stommel, 2017; Goodman \& Santangelo, 2011; Meedya, Fahy, \& Kable, 2010; Slootjes, McKinstry, \& Kenny, 2016). 


\section{Occupational Therapy's Current Role in Infant Feeding and Peri and Postnatal}

\section{Support}

Occupational therapists are addressing breastfeeding as an ADL and IADL (Foy, Loreman, \& Rudzinski, 2019). Occupational therapists are equipped to address feeding, eating, and swallowing associated with infant feeding (Paul \& D'Amico, 2013). They are present in addressing structure and function but are lacking in involvement in the maternal mental health side of breastfeeding (Boop \& Smith, 2017). Occupational therapists are also involved in postnatal care with mothers addressing carpal tunnel and De Quervains as a result of breastfeeding and bottle feeding (Grobbelaar Fernandes, 2018). Many researchers have called for occupational therapists to use their unique holistic approach to their clients in order to better serve the peri and postnatal community in breastfeeding (Grobbelaar Fernandes, 2018; Pitonyak, 2014; Slootjes, McKinstry, \& Kenny, 2016).

\section{Barriers to Breastfeeding}

Neifert and Bunik (2013) found that barriers to breastfeeding include a lack of prenatal education, the convenience of formula feeding, incorrect knowledge on infant crying, perception of insufficient milk supply, lack of support, maternal employment, and an early introduction of solid foods. The United States Surgeon General lists barriers to breastfeeding to include lack of knowledge, social norms, embarrassment, lactation problems, employment and childcare, and barriers to health services (General (US) et al., 2011). Keevash et al. (2018) found that ceasing breastfeeding is often not a choice but is needed due to the circumstances that women face postpartum that are made worse by a lack of education. 
Outside of physical barriers there are also psychological barriers that may prevent a woman from choosing to breastfeed. These may include pressure, shame, or false expectations of what breastfeeding will be like, especially with an infant with health complications (Bernaix et al., 2006; Gibbs, Boshoff, \& Stanley, 2016). Women who are unable to breastfeed must not be stigmatized and should be supported with information and resources to alternative feeding (Greenwood, 2018). Furthermore, mothers who are breastfeeding get different advice and feedback from providers creating confusion and frustration (Buchholz et al., 2016). General health professionals are not trained in depth on breastfeeding and thus the support is often inadequate for women struggling to breastfeed (de Almeida, de Araújo Barros \& da Veiga, 2015; Froehlich et al., 2015; Neifert \& Bunik, 2013). Casey, Fucile, and Dow (2018) found that strategic breastfeeding support prior to an infant's birth would better support the length of breastfeeding. In order for there to be sufficient breastfeeding support, interventions should be provided concurrently to women in a combination of settings including the home, community, and involved health systems (Sinha et al., 2015).

\section{The Psychosocial Impact on Women During the Transition to Motherhood}

Breastfeeding can often be perceived as "easy" or "natural," however, it is a complex and emotional experience for mothers (Buchholz et al., 2016, p. 1). One study found that mothers modify or sacrifice their routines in order to accommodate their infants' routines and needs (An, 2014). It was also found that a mother can be so focused on feeding their infant that she then sacrifices the ability to construct routines for both herself and her child thus endangering her role development as a mother (An, 2014; Froehlich et al., 2015; Horne, Corr, \& Earle, 2005). When mothers are supported in the 
role transition to motherhood, they are able to then take initiative of this transition and set goals for themselves. This initiative naturally leads to the development of self-efficacy within the role of a mother (An, 2014).

A mother experiences not only bodily changes during this transition but also mood changes related to hormones (Barrera, Wickham, \& Muñoz, 2015; Sacks, 2017). The effect and success of breastfeeding is related to a mother's emotional state (Borra, Iacovou, \& Sevilla, 2015; de Argolo Cerqueira, 2018). Van Scheppingen (2018) found that mothers feel a decrease in self-esteem for up to three years after childbirth. Van Scheppingen (2018) also found that for first-time mothers, relationship satisfaction had a sudden decrease around childbirth and then continued to decrease in the following years. Kanotra et al. (2007) found women needed more time in the hospital, more education and emotional support to help them adjust to lifestyle changes and new responsibilities at home. Lazarus \& Rossouw (2015) found that women connect the transition to motherhood in a positive and optimistic light, however, postnatal depression can occur when their expectations go unmet.

Improving the quality of life of mothers in turn improves the care for their infants (Barrera, Wickham, \& Muñoz, 2015). In order to provide the best care for mothers, the focus should be on her experiences breastfeeding and occupations associated with motherhood in order to increase support and ease suffering (Palmér \& Jutengren, 2019). George (2011) calls for occupational therapists to become more involved in the physical, mental, and emotional responsibilities associated with motherhood in order to better support the psychosocial impacts of motherhood. 


\section{Chapter III: Project Description}

The purpose of this capstone was to assess and explore the occupational needs of mothers associated with feeding their infants in a variety of ways. The needs of the mothers was assessed and a plan for future program development was created to enhance the role of occupational therapy in supporting the occupation of feeding, including breastfeeding, in order to promote self-advocacy skills in mothers and support their psychosocial and occupational lives through enhancing their roles, routines, rituals, and habits. Due to time restraints and cuts in funding, the needs assessment was prioritized over the development and implementation of a community program. This capstone project took place in Santa Barbara, California. The project was completed together with Welcome Every Baby (WEB) as well as many community partners. WEB is a home visitation program for infants and their families that focuses on the relationship between child and family as well as breastfeeding. WEB consists of registered nurses who are all certified in lactation. These home visits are free to the families and are performed 1-3 days after the mother returns home from the hospital and 2-3 weeks thereafter for a follow up visit. Other participating community partners included: Postpartum Education for Parents (PEP), First 5 Santa Barbara County, Carpinteria Children’s Project, Santa Barbara Cottage Hospital, Children's Medical Clinic, Santa Barbara Birth Center, Yoga Soup, UCSB Family Student Housing, Growing Babies Infant Center, The Early Years Infant Center, and Orfalea Children's Center.

\section{Materials and Design}

A needs assessment was performed using survey and interview methods. The purpose of this survey was to assess the feeding experiences of mothers and their 
transition to motherhood. The survey form developed for the purpose of this project consists of both closed and open-ended questions. The surveys were organized into an expectant mother (see Appendix B) and postpartum mother survey (see Appendix C) so that both populations could share their experiences. Both surveys also had an attached introduction in the form of a cover letter (see Appendix A). Questions were developed to focus on mother's routines, roles, and rituals around infant feeding. More detailed and personal questions regarding a mother's lived experience were asked through semistructured interviews (see Appendix D and E). If a mother had older children but was currently pregnant, she was still given the expectant mother survey and interview. The student took notes and direct quotes from each interview while maintaining confidentiality of the participants. Both survey and interview questions were used to assess the needs of the stated population as well as observations and conversations during home visits through WEB and the student's participation in various community programs. Themes were identified to determine the needs of mothers regarding the role and transition to motherhood in Santa Barbara County. These themes will serve as the focusses for the development of community services and classes in the future.

\section{Participants}

The participants in this capstone project included currently expecting mothers and mothers with an infant 0-12 months of age who were living in Santa Barbara county. Mothers were included in the needs assessment regardless of co-existing conditions in mother or infant. Participants were recruited during home visits with WEB or from their involvement in any of the community partners. Online survey links were widely distributed and spread by friends and colleagues to the student. Recruitment was 
performed in-person by the student during observations of home visits as well as by the WEB nurses who were trained in handing out the survey. Some women were recruited through their past participation in WEB or PEP, other health professionals, and word of mouth. Women who were given a hard copy received a cover letter explaining the capstone along with paid postage. On the cover letter a link to an online survey was also provided should a mother prefer to fill it out electronically. At the end of both written and electronic surveys a section was provided to either consent or deny further contact by student for a follow-up interview. The student contacted all consenting mothers by email first offering an option of an in-person interview and/or a proffered time and date for a phone call. Semi-structured interviews were performed, and women were given the option to terminate the interview at any time in order to decrease the burden of time on participants.

After reviewing the learned information from the surveys and interviews, themes were identified to determine mother's self-identified changes in roles, routines, and rituals, associated with the co-occupation of infant feeding. The determined occupational barriers experienced during the transition to motherhood then inspired program and educational recommendations for future community resources to be available to all mothers in Santa Barbara County, CA (see Appendix J).

Professionals working with mothers were not formally interviewed due to the focus on mother's personal experiences. However, the student took notes on each of the contacts in order to gain a better understanding of their roles and perceptions of mothers' needs in each of their communities. These professionals included lactation consultants, 
nurses, occupational therapists, a psychologist, a business owner of a women's clinic, and a researcher in infant feeding.

\section{Procedures and Timeline}

This capstone project began in November of 2019 and concluded in April 2020.

The capstone timeline (see Table 1) took place over sixteen total weeks. The outcome of this project was the sharing of discovered needs of mothers with Santa Barbara County community programs as well as plans to form community services and classes for mothers who may be experiencing occupational imbalance.

Table 1

Timeline

\begin{tabular}{|c|c|c|}
\hline Weeks & Tasks & \\
\hline Weeks 1-6 & $\begin{array}{l}0 \\
0 \\
0 \\
0 \\
0 \\
0\end{array}$ & $\begin{array}{l}\text { Introduction and rapport building with WEB staff } \\
\text { Introduction to other involved community programs } \\
\text { Early recruitment of participants } \\
\text { Familiarized self with WEB home visits to ensure no } \\
\text { overlap questions being asked of mothers } \\
\text { Observed mothers' environments and feeding experiences } \\
\text { Finalized needs assessment survey and interview } \\
\text { questions }\end{array}$ \\
\hline Weeks 7-12 & $\begin{array}{l}0 \\
0 \\
0 \\
0\end{array}$ & $\begin{array}{l}\text { Selected and recruited of participants } \\
\text { Began to distribute needs assessment surveys in-person } \\
\text { and shared online } \\
\text { Met with community partners } \\
\text { Attended local groups, classes, and conferences on infant } \\
\text { feeding }\end{array}$ \\
\hline Weeks 12-15 & $\begin{array}{l}0 \\
0 \\
0\end{array}$ & $\begin{array}{l}\text { Continued recruitment of mothers } \\
\text { Performed in-depth interviews } \\
\text { Analyzed qualitative data from surveys and interviews to } \\
\text { determine the needs of mothers } \\
\text { Organized needs into themes }\end{array}$ \\
\hline Week 16 & 0 & $\begin{array}{l}\text { Presented to community partners on promotion of } \\
\text { occupational therapy services in lactation and current } \\
\text { community programs }\end{array}$ \\
\hline
\end{tabular}




\section{Chapter IV: Results and Analysis}

\section{Data Analysis}

Data analysis consisted of collecting and identifying common themes in part from survey answers as well as in depth interview answers. Of the 95 women who filled out the hard-copy or online survey, 25 were expectant mothers and 70 were postpartum mothers with a 0-12-month-old. Of the 95 women who participated in the survey, 48 consented to be contacted further by the student for an interview. Of the 48 women who consented to an interview, 21 total mothers were interviewed due to their availability. The student reviewed both the survey answers and the detailed notes from the phone interviews in order to identify mother's common responses and organize then into themes. Themes were organized under subheadings of Infant Feeding, Motherhood, and Routines. The common identified themes were (1) Pressure, (2) Preconceived perceptions, (3) lack of confidence, (4) Identity Change, (5) Relationships, (6) Accessible resources, (7) Sleep, (8) Work, (9) Social, and (10) Self-care.

\section{Results}

Some of the general demographics of the mothers were collected for the benefit and use of WEB including: Mother's date of birth, zip code, how they heard about the survey, how many weeks pregnant/how many weeks when they delivered baby, age at birth of first baby, due date/delivery date, ages of other children, and income.

Sociodemographic results for the expectant and postpartum mother population that pertained to the student's capstone are listed below in Table 2.

Table 2

Sociodemographic of Expectant and Postpartum Participants 


\begin{tabular}{|c|c|c|c|c|}
\hline & $\mathrm{Ex} 1$ & Mothers & Pos & Mothers \\
\hline Variable & $\mathrm{N}$ & $\%$ & $\mathrm{~N}$ & $\%$ \\
\hline Planned/Actual Delivery type & & & & \\
\hline Vaginal & 18 & $72 \%$ & 56 & $81.2 \%$ \\
\hline Caesarean & 4 & $16 \%$ & 13 & $18.8 \%$ \\
\hline Undecided & 3 & $12 \%$ & & \\
\hline Marital Status & & & & \\
\hline $\begin{array}{r}\text { Continuously intact (two parent } \\
\text { household married or not) }\end{array}$ & 22 & $88 \%$ & 67 & $97.1 \%$ \\
\hline Divorced family & 1 & $4 \%$ & 0 & $0 \%$ \\
\hline Single parent, not divorced & 2 & $8 \%$ & 2 & $2.9 \%$ \\
\hline Highest level of education & & & & \\
\hline Bachelor's degree & 15 & $60 \%$ & 34 & $49.3 \%$ \\
\hline Graduate school or higher & 5 & $20 \%$ & 24 & $34.8 \%$ \\
\hline $\begin{array}{r}\text { Some college or technical } \\
\text { training }\end{array}$ & 3 & $12 \%$ & 9 & $13 \%$ \\
\hline High school graduate & 2 & $8 \%$ & 0 & $0 \%$ \\
\hline Less than high school & 0 & $0 \%$ & 2 & $2.9 \%$ \\
\hline Work Status & & & & \\
\hline Currently working & 19 & $76 \%$ & 20 & $29 \%$ \\
\hline Not working & 3 & $12 \%$ & 15 & $21.7 \%$ \\
\hline On leave & 3 & $12 \%$ & 34 & $49.3 \%$ \\
\hline School status & & & & \\
\hline Not in school & 25 & $100 \%$ & 57 & $83.8 \%$ \\
\hline
\end{tabular}




\begin{tabular}{r|llll} 
Undecided about returning & 1 & $4 \%$ & 2 & $2.9 \%$ \\
Currently in School & 0 & $0 \%$ & 7 & $10.3 \%$ \\
On leave & 0 & $0 \%$ & 3 & $4.3 \%$
\end{tabular}

\section{Expectant Mothers}

The ages of the participants who were currently pregnant ranged between $22-44$ years old and they were between 16-37 weeks pregnant. Fifteen respondents were firsttime mothers, seven were expecting their second child, two were expecting their third child, and 1 mother was expecting her fourth child. When asked how they planned to feed their baby, $100 \%$ of mothers said they planned to breastfeed, $64 \%$ planned to give expressed breast milk, and $28 \%$ planned to give formula. Two mothers planned to breastfeed under 6 months, thirteen mothers planned to breastfeed up to 6-12 months, 3 planned to breastfeed 12-18 months, 2 planned to breastfeed two years, and 3 mothers planned to breastfeed "as long as they can". When asked if anyone would help feed their baby, $78.3 \%$ of women said yes, while $21.7 \%$ said no. $96 \%$ of women reported that they had been given suggestions about how or where to get help if they were having problems feeding their baby. When asked how or where to get help women responded the hospital (79.2\%), from a health professional (50\%), calling a helpline/warmline (33.3\%), a home visitation program (70.8\%), a mother support group or peer (75\%), another community service (16.7\%), and a lactation consultant (4.2\%).

\section{Postpartum Mothers}

The ages of the participants who were postpartum ranged between 17-42 years old and they were had delivered between $34-42$ weeks pregnant. $62.3 \%$ of respondents were first-time mothers, $26.1 \%$ had two children, $8.7 \%$ had three children, $1.4 \%$ had four 
children, and $1.4 \%$ had five children. When asked how they feed their baby, $89.9 \%$ of mothers said they breastfeed, $37.7 \%$ give expressed breast milk, and $14.5 \%$ give formula, and $24.6 \%$ give solid foods. Three mothers plan to breastfeed $0-3$ months, four mothers plan to breastfeed up to 6 months, 1 mother planned to breastfeed 10 months, 17 mothers planned to breastfeed for or up to 1 year, 17 planned to breastfeed for more than a year, 6 planned to breastfeed until their baby self-weened. When asked if they were able to follow this plan after the birth of their baby, $86.8 \%$ of women said yes, with the remaining women either unable to complete their plan or still unsure if they will complete their breastfeeding plan. When asked if anyone would help feed their baby, $55.1 \%$ of women said yes, while $44.9 \%$ said no. $98.6 \%$ of women reported that they had been given suggestions about how or where to get help if they were having problems feeding their baby. When asked how or where to get help women responded the hospital $(82.4 \%)$, from a health professional (57.4\%), calling a helpline/warmline (32.4\%), a home visitation program (63.2\%), a mother support group or peer (67.6\%), and another community service $(23.5 \%)$.

\section{Expectant Mothers on Feeding}

Responses from the expectant mother's feelings on feeding are depicted in Appendix F. Overall, the majority of expectant mothers agreed that the breastfeeding education they received was helpful, felt prepared to feed their baby, felt confident about feeding their baby, knew what resources to use for help feeding their baby, and liked their current feeding plan. Most expectant mothers reported that their doctors had not addressed feeding (see Figure 4). A majority of expectant mothers also reported worrying about feeding their baby (see Figure 7). 


\section{Expectant Mothers on Motherhood}

Responses from the expectant mother's feelings on motherhood are depicted in Appendix G. Overall, the population of expectant mothers felt prepared to become a mother, felt confident in their role as a mother, felt supported as a mother, were enjoying pregnancy, were aware of resources for motherhood, and were able to maintain their relationships. There were more skewed responses for expectant mothers being able to participate in the same activities before pregnancy (see Figure 10) with a majority feeling neutral about it and the rest split between agreeing and not agreeing. The data was also skewed with whether or not women were able to get enough sleep each night (see Figure 17).

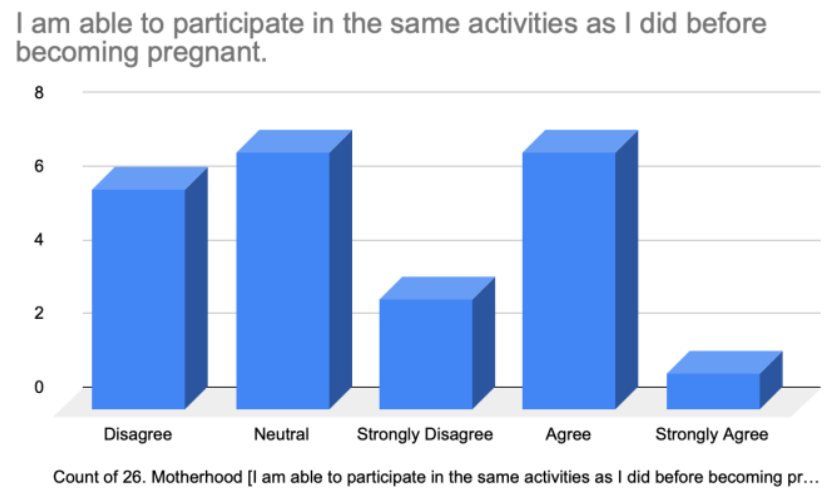

Figure 10. I am able to participate in the same activities as I did before becoming a mother.

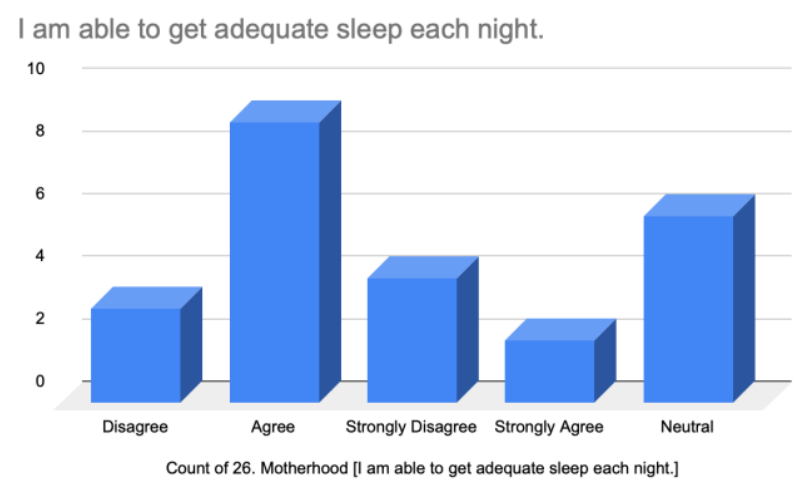

Figure 17. I am able to get adequate sleep each night. 


\section{Postpartum Mothers on Feeding}

Postpartum mothers generally agreed that the breastfeeding education and support they received was helpful, they felt prepared to feed their baby, they felt confident about feeding their baby, they knew what resources to use for help feeding their baby, and they liked their current feeding methods. Questions where responses were more skewed was worrying about feeding their baby and scheduling outings around feedings. Appendix $\mathrm{H}$ depicts postpartum mothers' responses on feeding their baby. The majority of postpartum mothers reported that they felt the breastfeeding education received was helpful, they felt prepared to feed their baby, they felt confident about feeding their baby, their pediatrician addressed feeding, they were aware of resources for feeding, they liked their current feeding methods, and they did not worry about feeding their baby. Women generally agreed that they scheduled outings around feedings, however answers were much for distributed than others (see Figure 25).

\section{Postpartum Mothers on Motherhood}

Appendix I represents postpartum mothers' responses on motherhood. The majority of the population of postpartum mothers responded that they felt prepared to become a mother, felt confident in their role as a mother, felt supported as a mother, knew what resources were available to help for being a mother, and were able to maintain their relationships. The majority of women felt neutral about being able to participate in the same activities as they had before becoming a mother (see Figure 28). A majority of women reported that motherhood was how they expected, although a large population also reported neutral feelings (see Figure 31). There were also skewed answers regarding 
mothers getting adequate sleep each night, with a slight majority reporting that they were able to (see Figure 34).

\section{In-depth Interviews}

During in depth phone interviews, mothers were asked to share about their plans and/or experiences for infant feeding, transition to motherhood, and routines (see Appendix D and E). Both expectant and postpartum mothers were given the opportunity to share about their past experiences of being a mother if they had other children and about any other changes they might have experienced during the transition to motherhood. Mothers were also asked WEB specific questions at the end for the use and benefit of their program. From each mother's lived experiences common themes and population needs emerged. These themes were identified and then categorized under infant feeding, motherhood and routines below.

Infant Feeding. Infant feeding emerged as a main theme for causing occupation disruption in mothers. This included breastfeeding, bottle feeding, preparing formula, and transitioning to solids. The main subthemes under infant feeding included pressure to feed their infant a certain way, preconceived perceptions on how feeding would be, and a lack of confidence in feeding their infants.

Pressure. Many mothers reported feeling pressure to feed their infant a certain way. This generally varied from pressure to breastfeed, exclusively breastfeed, or to not introduce bottle feeding to their infants. Mothers reported external pressures from family members, friends, health professionals, social media/internet, and even strangers. When asked about their experiences with external pressure, one mother shared, "She [a lactation 
consultant] made me feel like a bad mom." Another wanted more support in the form of a, "a non-judgmental group that supports all types of feeding, including formula."

The most reported feeling of pressure, however, was internal pressure from themselves due to the fact that many wanted to breastfeed so badly. One mom reported, "I put pressure on myself to do it because I wanted my baby to have a good immune system." This internal pressure was described by many moms as anxiousness or nervousness that they would not be able to breastfeed as long as their breastfeeding goal. A mother who experienced this shared, "Breastfeeding made me feel insecure because my milk wasn't coming in. In the hospital it made me sad that we had to switch to formula." For mothers who had already stopped breastfeeding, they described the pressure manifesting as shame over the fact that they were unable to feed their infant the way they desired. One mother described it as, "It's the worst feeling in the world to not be able to feed your newborn."

Preconceived perceptions. Many women reported their experiences with infant feeding as vastly different from what they had perceived prior to having their baby. Many women felt that they had not been prepared or told how difficult feeding, specifically breastfeeding, might be. They wished that their expectations would have been more prepared for their actual experiences, especially those who sought out prenatal education. A mother described it as, "No one tells you that breastfeeding is challenging and that it may not click right away." Some talked about how they had been told breastfeeding came naturally, so when they struggled one mother stated, "I just wasn't expecting it to be painful." Many mothers wished that there had been "someone to say how hard it was going to be" or that "even though you have a plan or vision things may be different." 
Another mother described her unmet expectations saying, "As much as I planned or prepared for breastfeeding, it didn't go as planned. It was painful, difficult and frustrating." Another mother recounted how she felt that she had been alone in her struggle stating, "I wish I had known that a lot of people had a hard time and that everyone doesn't enjoy it or that some women can't breastfeed."

Lack of confidence. The most reported stressor to mother's feeding experiences was worrying over whether the baby was getting enough nutrition to maintain and gain weight. This was reported the most often with mothers who were breastfeeding due to the fact that they could not see how much milk the baby was transferring. One mother described her breastfeeding experience as, “I didn't feel confident with any of it. I was questioning and doubting myself." Many women also reported feeling anxious or nervous that they weren't producing enough milk in breastfeeding, even if their baby was gaining normal weight. One mother wrote, "I am anxious I am not feeding her enough (though it is clear I am)." Some women reported that they only experienced lack of confidence when they were having difficulties. A mother described her experience as, "my confidence dipped when trying to wean off the nipple shield because it was painful, and my baby was frustrated. I'm a person who wants to do it right each time." Many mothers talked about how their lack of confidence stemmed from not knowing if certain experiences were "normal" in feeding and not knowing if they were "doing it right". Another woman shared that she might have exasperated her breastfeeding experience by over pumping due to lack of confidence that her baby was getting enough at breast. Another theme that emerged was a mother's lack of confidence brought on by health professionals in lactation giving differing opinions. One mother shared that in her 
experience "every lactation consultant said something different." Another said her experience with contradictory feeding advice was "tricky to discern" and made her lose confidence in her feeding abilities. One mother who was bottle feeding stated, 'I didn't feel confident when switching to formula. There was no training with bottle feeding."

Motherhood. The transition to motherhood originated as a main theme for causing occupation disruption in mothers. The sub themes included were the identity change in the transition to motherhood, relationships including sexual intimacy, and accessible resources.

Identity change. When sharing their experiences of pregnancy and postpartum, a common theme that arose was the huge identity sift that women experience becoming a mother, especially for the first time. In one interview, a mother described her first-time experience as becoming a mother:

I never got a chance to get ready for my baby because I was coping and grieving pre-parenthood life. The hardest thing has been how lonely motherhood is. It's like having a slate wiped clean. So many things fell away immediately and then a few months later I was so changed. Do I like my clothes? What food do I like? Do I like my relationship? It was an intense and complete realigning of my existence. The loneliness even around other mothers is still there because no one has same exact experience. It's such a singular experience, plus if you have a male partner no matter how much they want to help it's not the same. The baby is there and it's just you two.

There were many moms who spoke of feelings of isolation during this identity shift to becoming a mother. One said, "It was a very tough transition to being a mom. I was by 
myself with baby at home with no family nearby." Another mom spoke on her transition, "It was hard to find my identity and feel like myself outside of being a mother. Even in my friend group I wanted to talk about me and they were only asking about the baby." When mothers were asked what could make this life transition easier many spoke about a need for more maternal mental health support in the community. One mom said, "I think we would all be healthier and happier if we could talk to a professional about it. Someone who understands that vast changes that you go through in every sector of your life as well as your mind and body." Not only did women report a change in their emotional transformation but also their physical bodies. Mothers experienced joint pains, pelvic floor weakness, breast/nipple variations, hormonal alterations, night sweats, and birthing wounds. A mother described it as "you're donating your life being a mom."

Relationships. A majority population of the women who participated in the survey reported being in a current relationship. From this population, women commonly reported either a change in relationship roles with their partner or a change in their sex/intimacy. For one mother, who was exclusively breastfeeding, it was particularly stressful to have not feel like they were in equal roles. She shared, "If no one else can feed your baby then you are hanging by a thread because it's all on you. That wasn't talked about even with friends who have babies. I would have started bottle feeding sooner than I did because it would have saved my sanity so many times." Another mom shared, 'I've been trying to include [my partner] so we don't get separated by this process." Other mothers spoke about how their relationship felt put on pause, one mother expressing, "we are recognizing that this is a harder time in marriage, but still do what we can to respect our marriage and give it the time that it deserves." Another shared, "A lack 
of quality time has put a disconnect in our relationship and instead of our needs it's about our baby's needs. We contemplated counseling but we are too strained financially right now." Some mothers shared about how they and their partner weren't mentally prepared for the changes, saying "We're more apart than we expected to be because we're putting a lot in to kids." Another sharing, "This has been a giant lifestyle change and I had better perception than what he did. It's taking him awhile to catch up and understand that things won't be like before we had baby. This is the "new normal'." Another mother expressed, "Parenting brings out stuff in both of you that you didn't even know was there."

Changes in sex and intimacy was reported by every postpartum mother who was interviewed. Many reported feelings of pain or being uncomfortable during intercourse even after waiting the suggested six weeks. A mother shared, "we didn't want to have sex because it was painful" and expressed how she would have liked if her OB had normalized her feelings more. Several mothers who were pregnant or who had not reached 6 weeks of recovery also expressed feelings of unease over how their intimacy might change with one mother stating, "I worry about after [six weeks] with the balance of how I'm feeling and if it's going to be uncomfortable." Many mothers described changes in their sex drive as well. A mother shared, "I have zero sex drive even though I'm still attracted to my partner." Another felt, "I want to have sex because of him but I don't have the desire too," Another shared, "I wouldn't say I have a sex drive, but I feel like I need to do it and initiate after a few days when we find the time. I'm needing to be mindful to have sex."

Accessible resources. A majority of mothers were able to name many resources available in their town. However, many reported that although the resources were there, 
they did not feel necessarily accessible or "out of reach on a practical level." Mothers reported home care services as being very valuable due to the fact that they were available in their own environment and they did not have to prepare to leave the house. One mother felt that the current community support groups are, "not great for working moms and they're not directed to low income families. These programs aren't realistic to many women."

When asked how the community could better support them, many women asked for increased home services and support after giving birth. A mother described this as, "I wish there were professionals in the community that could come to your house for counseling to help you through the transitions of being a mom. I know there's [resources] but anything that's scheduled is so hard and I don't know how I'll feel that day." Another mother reported, "There's a huge piece missing in terms a maternal care. I had a c-section and was not expecting it. For the first two weeks I couldn't move or walk. My husband had to do everything." Another mother felt, "More [support] is needed postpartum. Things now are so child focused and not health and wellness for mother."

Routines. Routines emerged as a main theme for causing occupation imbalance in mothers. Subthemes of overall routines were listed under sleep, work, social participation, and self-care.

Sleep. Majority of participants identified adequate sleep as a crucial need in order to be able to complete necessary daily occupations. Expectant mothers reported sleep disturbances and postpartum mothers talked about "feeling like [they'd] never sleep again" in the first weeks/months after giving birth. A mother stated, "It took so long to fall into a routine. I finally feel sane now that we're all sleeping again." Another mom 
said, "Sleep was hell until 7 months. I am now rigid on a schedule because she has to have a nap so that she's not a nightmare at night because then it's all on me." Another mom shared that her lack of sleep came from her symptoms of postpartum anxiety and depression saying, "when we transitioned to the crib, I had insomnia thinking she wasn't going to live even though I knew it was irrational." Other moms shared about how lack of sleep added to their responsibilities, "When you're not sleeping you feel sick and you have to take care of yourself and another human." Another mom shared how she felt unprepared for the lack of sleep saying, "Everything is so baby focused and as a mother it's a crazy shock that you're not sleeping." Others spoke about how much it affected them emotionally, "Be prepared that you're not sleeping and your emotions are through the roof. I was happy and would sporadically cry or was crying because it was so hard." Another mom said, "I would cry multiple times a week saying I can't live like this."

Work. A large portion of the mothers interviewed shared stories of how their work was affected after becoming a mother. One mother shared about her fear of going to her coworkers to ask for time off saying, "It was hard to go to women without children who didn't understand that I wanted that much time off." Due to the stressors of trying to maintain her breastfeeding goals one mother reported, "I withdrew from a job recruitment because I was concerned of not getting my own office to pump." Other mothers blamed going back to work as the reasons they had to switch to alternative feeding measures. A mother shared, "Going back and being away from the baby made my supply drop. I was in a bad headspace the first few months going back but was eager to prove that I could." Another mom shared how pumping at work was stressful to her as well saying, 
It was really hard because I didn't have enough milk and I was trying to pump at work and manage my schedule. I ate less at work because I was trying to pump during my lunch break. My schedule was tight in order to be able to leave and pick up my baby on time. It only improved after switching to formula.

Countless others talked about worry and anxiety over going back to work, one mother stating, "I don't really have a choice or else I'd lose my job and my career." Another mother who was pumping at work shared, "I'm struggling to keep up with work with the same productivity expectations." Despite laws in place, many women reported that they did not have an adequate place to pump at work. One mother had to "kick someone out of their office to pump" and another reported that her only option was an out of service restroom. On top of the stressors of going back to work and maintaining work, many women also reported the difficulties in finding childcare support. One mother shared, "Finding childcare has been a nightmare because all the waitlists are crazy."

Social. Mothers reported having their social participation affected during pregnancy and after giving birth. One mother reported, "I have lost friends because I have not been as social as before, especially with friends who don't have babies." Another mom shared about her struggle to balance social participation into her routine stating, "we're very social but we've had to cut way back." Another mom shared that after having a baby she felt "forced to be around other moms". She went on to say in her experience, “it's hard to make new friends and it's hard to keep up old friendships. Social life is just really complicated."

Self-care. Many women reported that they could no longer participate in the same activities they did before pregnancy and having a baby. When asked further in interviews, 
the majority of the women named self-care as the most lacking activity. Many women felt they didn't have the luxury to spend time on themselves. One sharing, "Your health gets pushed on the back burner and I felt that no one could take care of me. It was hard to even feed myself." Many other women named physical activity as being something they did for themselves but could no longer participate in or participate in the same way. A mother stated, "The hardest part is not having freedom to go on a run or go to yoga. It can be frustrating. A little time here and there to myself would help." Other women talked about how even when they have the "time" for some self-care they are busy with responsibilities. A mother shared, "When I have a day off, I'm doing housework, chores, and errands not things for myself." Another women felt, "It's the feeling that they need you physically the whole time. Your freedom is gone."

\section{CHAPTER V: Discussion and Conclusion}

\section{Discussion}

The goal of this capstone project was to better understand the lived experiences of mothers in order to improve support and educate in maternal role transition and infant feeding. The participants in this project defined various needs as an expectant and postpartum mother. Through a detailed needs assessment, gaps in supports were identified for the transition to motherhood and in infant feeding. The survey results and themes from interviews suggest a need for increased participation of occupational therapists in maternal mental health, infant feeding, and motherhood routines.

The survey results suggested that the majority of women were generally confident in infant feeding practices and the role transition to becoming a mother. However, when the in-depth interviews were performed and women were allowed to expand and expound 
upon their feelings, they seemingly appeared less confident than survey answers by their current or past experiences. Themes were created mainly from these interviews since they were in-depth, genuine representations of mothers' lived experiences in their own words.

These thematic findings were consistent with literature on the barriers to infant feeding, specifically breastfeeding. In the survey results, $100 \%$ of the women (expectant and postpartum) reported wanting to breastfeed for a certain amount of time. While some were still in progress or had been able to reach their breastfeeding goal, there were several who were not able to attain this goal. According to research, this points to an absence or gap in support systems. We see in the interviews that the mixture of a feeling of pressure to feed a certain way, preconceived perceptions of how feeding will be, and lack of confidence in their feeding method leads mothers to terminate breastfeeding, often unwillingly. In order to improve breastfeeding rates and help women reach their breastfeeding goals, counselling and education need to be provided synchronously in home and community, health systems and community, and health systems and home in order to empower mothers to resolve breastfeeding difficulties by increasing self-efficacy (Sinha et al., 2015).

The results of this needs assessment also aligned with the literature on the psychosocial impacts on women during the transition to motherhood. In interviews mothers reported vast changes in their identity, relationship, and body. Many shared that they would have liked more support which suggests a lack of maternal care in the community in line with research findings that mothers often report feeling "uncared for" (Stone \& Kokanovic, 2016). Mothers reported increased difficulty managing their relationship and intimacy with their partners. This also related to women reporting 
decrease in self-esteem due to experiencing so many body and hormonal changes affecting their sex drive and emotional lability (Van Scheppingen, 2018).

The student promoted the importance of the role of occupational therapy in services such as WEB and showed continued need of such skills to other community partners in the form of a presentation. The student envisions future research on the needs of mothers and the significance of improved community services in order to generalize the results to the population of mothers as a whole. Occupational therapists are equipped to be a part of the collaborate team before and after birth to better support women during pregnancy and as they transition into motherhood. If there is an increase in community support for mothers in Santa Barbara County, research suggests that breastfeeding rates will increase as well (CDC, 2016).

Mothers sacrifice their sleep, social, and self-care routines in order to prioritize their infants' routines and needs (An, 2014). In this needs assessment mothers often reported sleep deprivation due to anxiety, being uncomfortable, or night feedings. Many sacrificed work opportunities in order to maintain their breastfeeding goals and many had negative pumping experiences in the workplace. Women described challenges in their ability to socialize and participate in self-care activities, particularly exercise.

\section{Limitations}

This capstone has limitations due to available resources. The surveys were not able to be translated to Spanish in time for distribution. This could have limited Spanishonly speaking populations form taking the survey and participating in interviews. To the best of the student's abilities, surveys were distributed to populations of various socioeconomic populations, however, most participants reported a family income of 
$\$ 75,000$ or more per year. The population who was interviewed was limited to those who consented to further contact on the surveys which may include women who have necessary resources and support to have the time to answer further questions. Probing questions helped to develop relationships during the phone interviews which in turn yielded more vulnerable answers from women that often differed from their own survey answers. These were taken into account when creating themes since they represented more vulnerable answers. The end of this capstone took place during the COVID-19 pandemic. Women were less available during this time and in order for the interviews to not be a burden, the student terminated reach outs a week earlier than anticipated. Lastly, themes for the results were determined through the student analyzing surveys and interviews and not coding which may affect validity of the capstone project.

\section{Implications for Occupational Therapy}

This capstone project suggests that occupational therapists have a large role to play in maternal mental health and the lactation community. As mothers continue to ask for more support before giving birth and postpartum, occupational therapists need to increase their participation in lactation and fill gaps in services to assist women in the transition to motherhood. By supporting the role transition and increasing the quality of life in mothers, occupational therapists can address a mother's routines around infant feeding and help them adjust to the vast lifestyle changes (Kanotra et al., 2007). Occupational therapists can also participate as collaborative team members in addressing sexual intimacy and the pelvic floor before and after giving birth and address new roles in their relationship. In order to normalize the intense mental and physical transitions that 
mothers face, occupational therapists can educate women during pregnancy and follow up with community and home support.

When mothers are supported in their role as a mother, they begin to take initiative of this transition and set goals for themselves. This inherently leads to the development of self-efficacy within the role of a mother (An, 2014). If occupational therapists focus on improving the quality of life of mothers it will in turn improve the infants health and wellness (Barrera, Wickham, \& Muñoz, 2015). Occupational therapists have the opportunity and are fully equipped to advocate for mothers and de-stigmatize infant feeding and the transition to motherhood by improving care to mothers through supporting and assisting in role transition. Occupational therapists need to become more involved in the physical, mental, and emotional burdens associated mothers face in order to better support the psychosocial impacts of motherhood (George, 2011). Occupational therapists have the opportunity to close the gap in the literature and address breastfeeding disparities through maternal knowledge and self-efficacy in infant feeding (Alghamdi, Horodynski, \& Stommel, 2017; Goodman \& Santangelo, 2011; Meedya, Fahy, \& Kable, 2010; Slootjes, McKinstry, \& Kenny, 2016).

\section{Conclusion}

In conclusion, this paper supports how occupational therapists can become more involved in the lactation community in order to better support mothers in their transition to motherhood and infant feeding experiences. Furthermore, needs of expectant and postpartum mothers were identified and shared to increase community support in Santa Barbara County. Occupational therapists are equipped to help prepare and educate expectant mothers in the role transition to motherhood as well as provide direct 
intervention to postpartum mothers requiring assistance in shifting roles and routines around infant feeding and maternal mental health. Occupational therapists are a critical member to the collaborative team for expectant and postpartum mothers in order to continue to transform society to better support breastfeeding and maternal mental health. Occupational therapists are the best equipped to address the broad occupations of a mother, the vast and intimate routines involved in motherhood, and the psychosocial joys and sorrows that motherhood impacts upon women (Froehlich et al., 2015). 


\section{References}

Ahluwalia, I. B., Morrow, B., \& Hsia, J. (2005). Why do women stop breastfeeding? Findings from the pregnancy risk assessment and monitoring system. Pediatrics, (6), 1408.

American Academy of Pediatrics. (2018). Benefits of Breastfeeding. Retrieved from https://www.aap.org/en-us/advocacy-and-policy/aap-healthinitiatives/Breastfeeding/Pages/Benefits-of- Breastfeeding.aspx

Alghamdi, S., Horodynski, M., \& Stommel, M. (2017). Racial and ethnic differences in breastfeeding, maternal knowledge, and self-efficacy among low-income mothers. Applied Nursing Research, 37, 24-27.

American Occupational Therapy Association. (2014). Occupational therapy practice framework: Domain and process (3rd ed.). American Journal of Occupational Therapy, 68(Suppl. 1), S1-S48.

An, S.-J. L. (2014). Occupation-Based Family-Centered Therapy Approach for Young Children with Feeding Problems in South Korea; A Case Study. Occupational Therapy International, 21(1), 33-41.

Anaby R., Backman L., \& Jarus T. (2010). Measuring occupational balance: A theoretical exploration of two approaches. Canadian Journal of Occupational Therapy, 77(5), 280-288. https://doi-org.prx-usa.lirn.net/10.2182/cjot.2010.77.5.4

Barrera, A. Z., Wickham, R. E., \& Muñoz, R. F. (2015). Online prevention of postpartum depression for Spanish- and English-speaking pregnant women: A pilot randomized controlled trial. Internet Interventions, 2(3), 257-265.

Bernaix LW, Schmidt CA, Jamerson PA, Seiter L, \& Smith J. (2006). The NICU 
experience of lactation and its relationship to family management style. $M C N$ :

The American Journal of Maternal Child Nursing, 31(2), 95-100.

Boop, C., \& Smith, J. (2017). The practice of occupational therapy in feeding, eating, and swallowing. American Journal of Occupational Therapy, 71. https://doi.org/10.5014/ajot.2017.716S04

Borra, C., Iacovou, M., \& Sevilla, A. (2015). New Evidence on Breastfeeding and Postpartum Depression: The Importance of Understanding Women's Intentions. Maternal and Child Health Journal, 19(4), 897-907.

Buchholz, M., Dunn, D. M., Watkins, L., \& Bunik, M. (2016). Integrating Infant Mental Health with Breastfeeding Support: Five Years of the Trifecta Approach. Newborn and Infant Nursing Reviews, 16(4), 293-297.

Casey, L., Fucile, S., \& Dow, K. E. (2018). Determinants of Successful Direct Breastfeeding at Hospital Discharge in High-Risk Premature Infants. Breastfeeding Medicine, 13(5), 346-351.

Centers for Disease Control and Prevention. (2016). CDC Newsroom. Retrieved from https://www.cdc.gov/media/releases/2016/p0822-breastfeeding-rates.html de Almeida, J. M., de Araújo Barros Luz, S., \& da Veiga Ued, F. (2015). Support of breastfeeding by health professionals: integrative review of the literature. Revista Paulista de Pediatria (English Edition), 33(3), 355-362.

de Argolo Cerqueira, P., Amorim, L. D. A. F., de O. Vieira, T., Dias, J. S., Brandao, H. V., \& Vieira, G. O. (2018). Defining Behavior Patterns Towards Exclusive Breastfeeding Using Latent Class Analysis. Journal of Pediatrics Review, 6(1), 17. 
Foy, C., Loreman, L., \& Rudzinski, T. (2019, March 25). Breastfeeding and Postnatal Support: A Community Partnership. Retrieved August 8, 2019, from https://www.aota.org/Publications-News/otp/Archive/2019/postnatal-care.aspx

Froehlich, J., Donovan, A., Ravlin, E., Fortier, A., North, J., \& Bloch, M. K. S. (2015). Daily routines of breastfeeding mothers. Work, 50(3), 433-442. https://doiorg.prx-usa.lirn.net/10.3233/WOR-141954

General (US), O. of the S., Prevention (US), C. for D. C. and, \& Health (US), O. on W. (2011). Barriers to Breastfeeding in the United States. Retrieved from https://www.ncbi.nlm.nih.gov/books/NBK52688/

George, M. (2011). Proposed Role for Occupational Therapy to Serve New Mothers, 14. Gibbs, D. P., Boshoff, K., \& Stanley, M. J. (2016). The acquisition of parenting occupations in neonatal intensive care: A preliminary perspective: Perspective préliminaire sur l'acquisition des occupations parentales dans les unités néonatales de soins intensifs. The Canadian Journal of Occupational Therapy; Ottawa, 83(2), 91-102.

Goodman, J. H., \& Santangelo, G. (2011). Group treatment for postpartum depression: a systematic review. Archives of Women's Mental Health, 14(4), 277-293.

Greenwood, M. (2018, July 8). US turned to threats to fight breastfeeding resolution: report [Text]. Retrieved January 15, 2019, from https://thehill.com/policy/international/396025-us-turned-to-threats-to-fightbreast-feeding-resolution-report

Grobbelaar Fernandes, J. (2018). THE ISSUE IS ... Occupational Therapists' Role in 
Perinatal Care: A Health Promotion Approach. American Journal of Occupational Therapy, 72(5), 1-4.

Hinde, K. (2016). What we don't know about mother's milk [Video file]. Retrieved from https://www.ted.com/talks/katie_hinde_what_we_don_t_know_about_mother_s_ milk

Horne J, Corr S, \& Earle S. (2005). Becoming a mother: Occupational change in first time motherhood. Journal of Occupational Science, 12(3), 176-183.

Hurst, N. M. (2007). Feature: Recognizing and Treating Delayed or Failed Lactogenesis II. Journal of Midwifery and Women's Health, 52, 588-594. https://doi-org.prxusa.lirn.net/10.1016/j.jmwh.2007.05.005

Kalmuss, D., Davidson, A., \& Cushman, L. (1992). Parenting expectations, experiences, and adjustment to parenthood: A test of the violated expectations framework. Journal of Marriage and the Family, (3), 516.

Kanotra S, D’Angelo D, Phares TM, Morrow B, Barfield WD, \& Lansky A. (2007). Challenges faced by new mothers in the early postpartum period: an analysis of comment data from the 2000 Pregnancy Risk Assessment Monitoring System (PRAMS) survey. Maternal \& Child Health Journal, 11(6), 549-558.

Keevash, J., Norman, A., Forrest, H., \& Mortimer, S. (2018). What influences women to stop or continue breastfeeding? A thematic analysis. British Journal of Midwifery, 26(10), 651-658.

Kurtz, S., Levine, J., \& Safyer, M. (2017). Ask the Question: Screening for Postpartum Mood and Anxiety Disorders in Pediatric Primary Care. Current Problems in Pediatric and Adolescent Health Care, 47(10), 241-253. 
Larson EA. (2000). Mothering: Letting go of the past ideal and valuing the real. American Journal of Occupational Therapy 2000; 54: 249-251.

Lazarus, K., \& Rossouw, P. (2015). mothers' expectations of parenthood: the impact of prenatal expectations on self-esteem, depression, anxiety, and stress post birth. INTERNATIONAL JOURNAL OF NEUROPSYCHOTHERAPY, 3(2), 23.

Meedya, S., Fahy, K., \& Kable, A. (2010). Factors that positively influence breastfeeding duration to 6 months: A literature review. Women \& Birth, 23(4), 135.

Neifert, M., \& Bunik, M. (2013). Overcoming Clinical Barriers to Exclusive Breastfeeding. The Pediatric Clinics of North America, 60, 115-145. https://doiorg.prX-usa.lirn.net/10.1016/j.pcl.2012.12.001

Palmér, L., \& Jutengren, G. (2019). Development and psychometric testing of an instrument to assess existential aspects of mother's initial breastfeeding difficulties (ExBreastS). Sexual \& Reproductive Healthcare, 19, 88-94. https://doi.org/10.1016/j.srhc.2019.01.005

Paul, S., \& D'Amico, M. (2013). The role of occupational therapy in the management of feeding and swallowing disorders. New Zealand Journal of Occupational Therapy, 60(2), 27-31.

Pearson, C. (2019). Why Breastfeeding Guilt Is So Hard To Shake. Retrieved from https://www.huffpost.com/entry/why-breastfeeding-guilt-is-so-hard-toshake_n_5c2a3e72e4b05c88b7029201?fbclid=IwAR1ClytFISUfc9J27BR_7clgDhOyxYR38oI1kKO2AvWFkebFCAYbrHAY_w

Pitonyak, J. S. (2014). Occupational Therapy and Breastfeeding Promotion: Our Role in Societal Health. American Journal of Occupational Therapy, 68(3), e90-e96 
Pizur-Barnekow, K. (2010). Maternal Health After the Birth of a Medically Complex Infant: Setting the Context for Evaluation of Co-Occupational Performance. American Journal of Occupational Therapy, 64(4), 642-649.

Price P, \& Miner S. (2009). Extraordinarily ordinary moments of co-occupation in a neonatal intensive care unit. OTJR: Occupation, Participation \& Health, 29(2), $72-78$.

Sacks, A., \& M.d. (2017). The Birth of a Mother. The New York Times. Retrieved from https://www.nytimes.com/2017/05/08/well/family/the-birth-of-a-mother.html

Sinha, B., Chowdhury, R., Sankar, M. J., Martines, J., Taneja, S., Mazumder, S., Bhandari, N. (2015). Interventions to improve breastfeeding outcomes: A systematic review and meta-analysis. Acta Paediatrica, (S467), 114.

Slootjes, H., McKinstry, C., \& Kenny, A. (2016). Maternal role transition: Why new mothers need occupational therapists. Australian Occupational Therapy Journal, 63(2), 130-133.

Stone, M., \& Kokanovic, R. (2016). "Halfway towards recovery": Rehabilitating the relational self in narratives of postnatal depression. Social Science \& Medicine, $163,98-106$.

Thulier, D., \& Mercer, J. (2009). IN REVIEW: Variables Associated With Breastfeeding Duration. Journal of Obstetric, Gynecologic \& Neonatal Nursing, 38, 259-268. https://doi.org/10.1111/j.1552-6909.2009.01021.x

Tully, K. P., Stuebe, A. M., \& Verbiest, S. B. (2017). Clinical Opinion: The fourth trimester: a critical transition period with unmet maternal health needs. American 
Journal of Obstetrics and Gynecology, 217, 37-41.

https://doi.org/10.1016/j.ajog.2017.03.032

Tuteur, A. (2019). Research Shows We Shouldn't Always Recommend Breastfeeding. Why Haven't We Stopped? Retrieved from https://slate.com/technology/2019/01/breastfeeding-mothers-recommendationsnot-universal.html?fbclid=IwAR1-EAcEJ-LEJinSuE6s 1ZCWxvHTk9L9of9gorklVWySLQ2wv25GK-23fA

U.S. Department of Health and Human Services. (2010). Maternal, infant, and child health. Retrieved from http://www.healthypeople. gov/2020/topicsobjectives2020/objectives- list.aspx?topicId5 van Scheppingen, M. A., Denissen, J. J. A., Chung, J. M., Tambs, K., \& Bleidorn, W. (2018). Self-Esteem and Relationship Satisfaction During the Transition to Motherhood. Journal of Personality \& Social Psychology, 114(6), 973-991.

Wilkins, C. (2006). A qualitative study exploring the support needs of first-time mothers on their journey towards intuitive parenting. Midwifery, 22, 169-180. https://doiorg.prx-usa.lirn.net/10.1016/j.midw.2005.07.001

World Health Organization. (2018). Breastfeeding. Retrieved from https://www.who.int/topics/breastfeeding/en/ 


\title{
Appendix A
}

\author{
Needs Assessment Survey Cover Letter
}

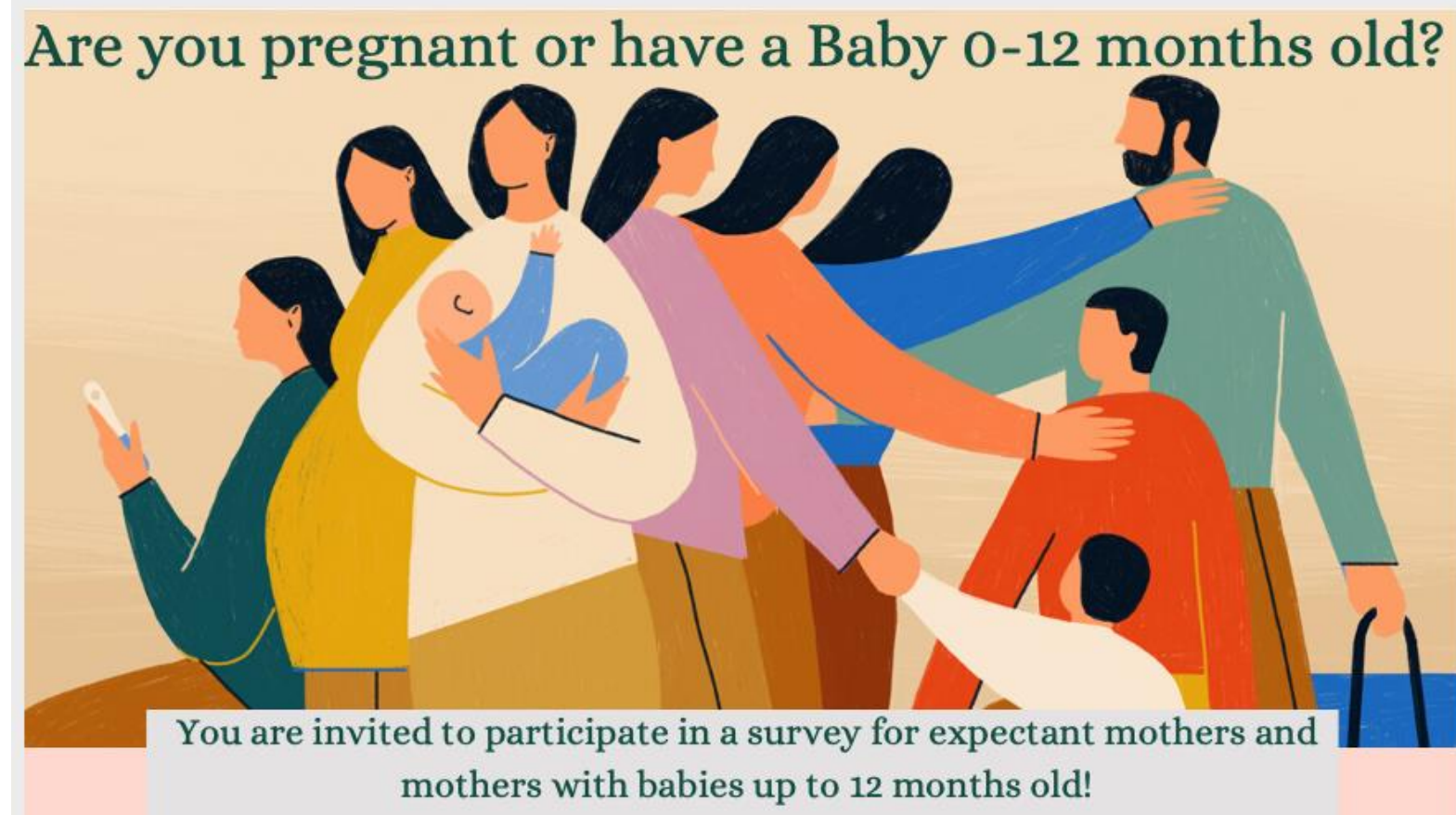

My name is Beth Vidmar. I am a graduate student in the department of occupational therapy at the University of St. Augustine for Health Sciences. I am interning with Welcome Every Baby Family Connects (WEB FC) and conducting a needs assessment on the transition to motherhood around feeding your baby. It's my hope that through these surveys, we'll learn more about the best ways to support mothers in feeding their babies.

You're invited to participate in this survey by filling out one online survey link below or one written version (mailing it back to us in provided stamped envelope). Please fill out only one survey per mother. All answers are confidential, and you won't be contacted about your answers unless you have stated so on the survey. Participation is voluntary and it's up to you whether or not you choose to answer any or all of the questions. There's no penalty or loss of benefits to which you are otherwise entitled if you choose not to participate or discontinue participation at any time. The information from these surveys will be used to help identify the additional needs of mothers in our community.

If you have any questions about this survey, please contact me at $\square$ or email at b.vidmar@usa.edu. If you would prefer a text with the survey link or a written version with postage, please contact me.

Thank you so much for your time - I know it is precious! Sincerely,

Beth Vidmar, OTDS

University of St Augustive for Health 700 Windy Point Dente

URLs to online surveys:

Expectant mother: https://forms.gle/yXtouQDPFemjYzwn7 Postpartum mother: https://forms.gle/Zj43rdHJ7P3pTZ2Y8 


\section{Appendix B}

\section{Needs Assessment Survey- Expectant Mother}

Survey for Expectant Mother

This survey relates to your youngest child only. It is completely confidential, and you will not be contacted unless you have noted so on the bottom of the page. This survey is also available online at https://forms.gle/6yFh6ex4AGJb78179

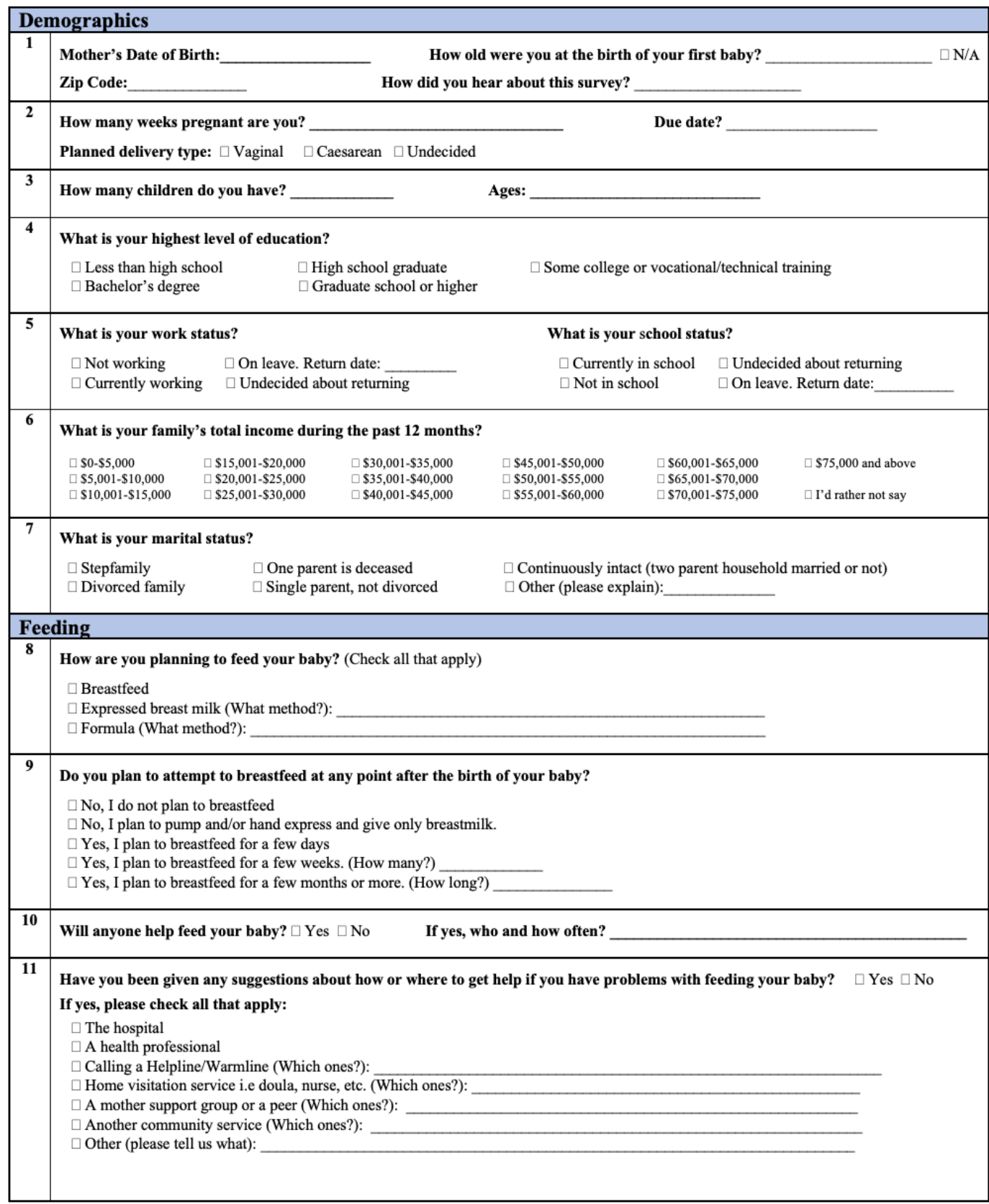




\begin{tabular}{|c|c|c|c|c|c|c|c|}
\hline \multicolumn{8}{|c|}{ Feeding Continued } \\
\hline & Please circle one. & $\mathbf{N} / \mathbf{A}$ & \begin{tabular}{c}
$\begin{array}{c}\text { Strongly } \\
\text { Disagree }\end{array}$ \\
\hdashline
\end{tabular} & Disagree & Neutral & Agree & 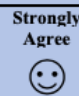 \\
\hline 12 & $\begin{array}{l}\text { The breastfeeding education I have received was helpful. } \\
\text { Explain: }\end{array}$ & 0 & 1 & 2 & 3 & 4 & 5 \\
\hline 13 & I feel prepared to feed my baby. & 0 & 1 & 2 & 3 & 4 & 5 \\
\hline 14 & I feel confident about feeding my baby. & 0 & 1 & 2 & 3 & 4 & 5 \\
\hline 15 & My doctor has addressed feeding my baby with me. & 0 & 1 & 2 & 3 & 4 & 5 \\
\hline 16 & $\begin{array}{l}\text { I know what resources to use if I have trouble feeding my baby. } \\
\text { List/Comments: }\end{array}$ & 0 & 1 & 2 & 3 & 4 & 5 \\
\hline 17 & I like my current feeding plan. & 0 & 1 & 2 & 3 & 4 & 5 \\
\hline 18 & $\begin{array}{l}\text { I worry about feeding my baby. } \\
\text { Explain: }\end{array}$ & 0 & 1 & 2 & 3 & 4 & 5 \\
\hline \multicolumn{8}{|c|}{ Motherhood } \\
\hline 19 & I feel prepared to become a new mother with this pregnancy. & 0 & 1 & 2 & 3 & 4 & 5 \\
\hline 20 & I feel confident in my role as a mother with this pregnancy. & 0 & 1 & 2 & 3 & 4 & 5 \\
\hline 21 & $\begin{array}{l}\text { I am able to participate in the same activities as I did before becoming } \\
\text { pregnant. }\end{array}$ & 0 & 1 & 2 & 3 & 4 & 5 \\
\hline 22 & I feel supported by my family and friends in my role as a mother. & 0 & 1 & 2 & 3 & 4 & 5 \\
\hline 23 & $\begin{array}{l}\text { I feel supported by my community (people outside my family and } \\
\text { friends) in my role as a mother. (i.e. work, groups, pediatrician etc.) }\end{array}$ & 0 & 1 & 2 & 3 & 4 & 5 \\
\hline 24 & This has been a physically comfortable and easy pregnancy for me. & 0 & 1 & 2 & 3 & 4 & 5 \\
\hline 25 & I am enjoying this pregnancy. & 0 & 1 & 2 & 3 & 4 & 5 \\
\hline 26 & $\begin{array}{l}\text { I am aware of resources to help me with the transition to motherhood. } \\
\text { List/Comments: }\end{array}$ & 0 & 1 & 2 & 3 & 4 & 5 \\
\hline 27 & $\begin{array}{l}\text { I have been able to maintain my relationships since becoming } \\
\text { pregnant. }\end{array}$ & 0 & 1 & 2 & 3 & 4 & 5 \\
\hline 28 & I am able to get adequate sleep each night. & 0 & 1 & 2 & 3 & 4 & 5 \\
\hline 29 & \multicolumn{7}{|c|}{$\begin{array}{l}\text { What has been your favorite thing about being pregnant? } \\
\text { What has been the hardest thing about being pregnant? }\end{array}$} \\
\hline 30 & \multicolumn{7}{|c|}{$\begin{array}{l}\text { Would you like to be contacted by Beth Vidmar to participate in a brief interview regarding your pregnancy or motherhood experience? } \\
\square \text { Yes, I would like to be contacted to participate in a brief interview. }\end{array}$} \\
\hline & Name: & & & Email: & & & \\
\hline
\end{tabular}




\title{
Appendix C
}

\section{Needs Assessment Survey- Postpartum Mother}

\begin{abstract}
Survey for Postpartum Mother
This survey relates to your youngest child only. It is completely confidential, and you will not be contacted unless you have noted so on the bottom of the page. This survey is also available online at https://forms.gle/ieAnGi4oJMXjAvyH6
\end{abstract}

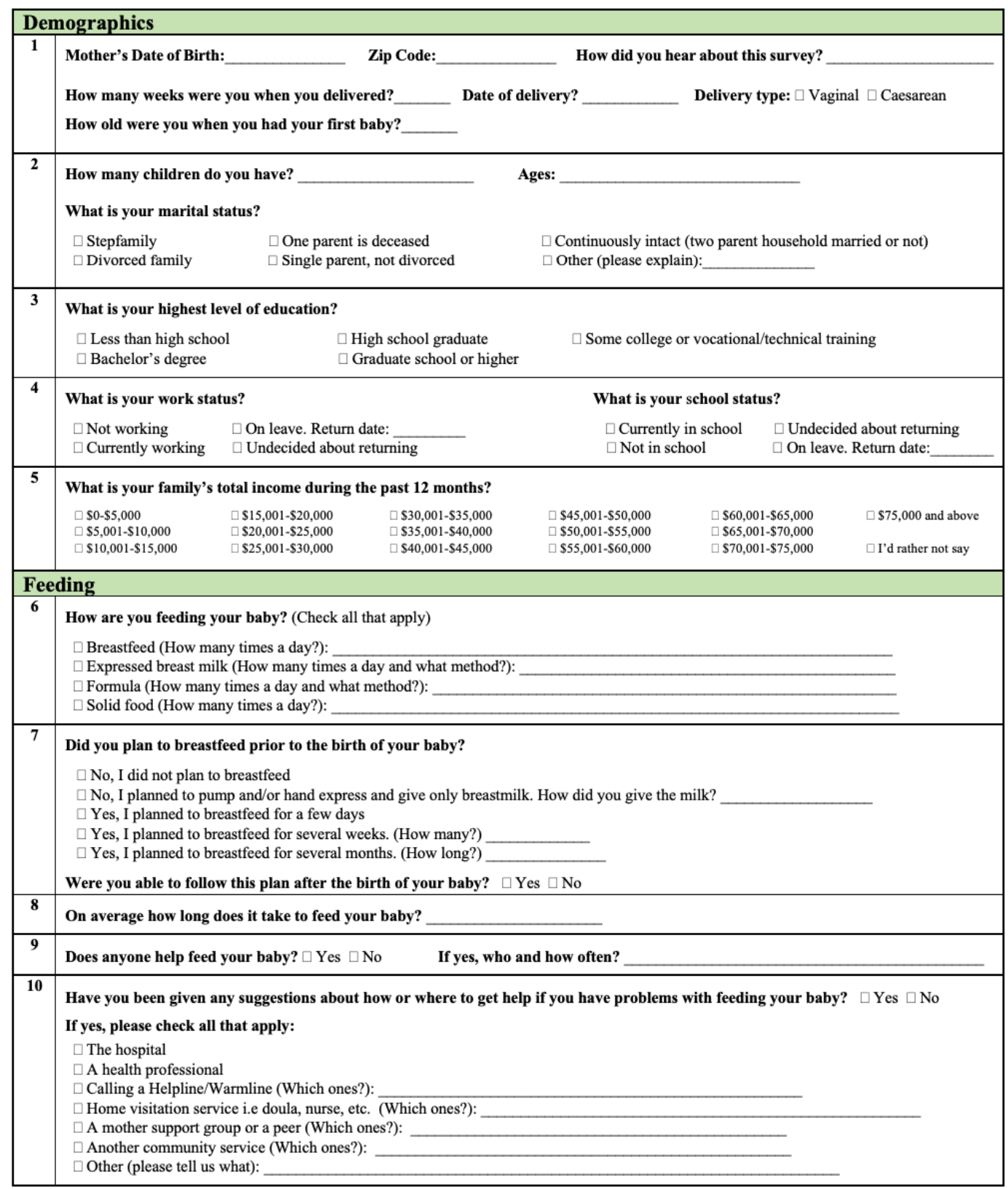




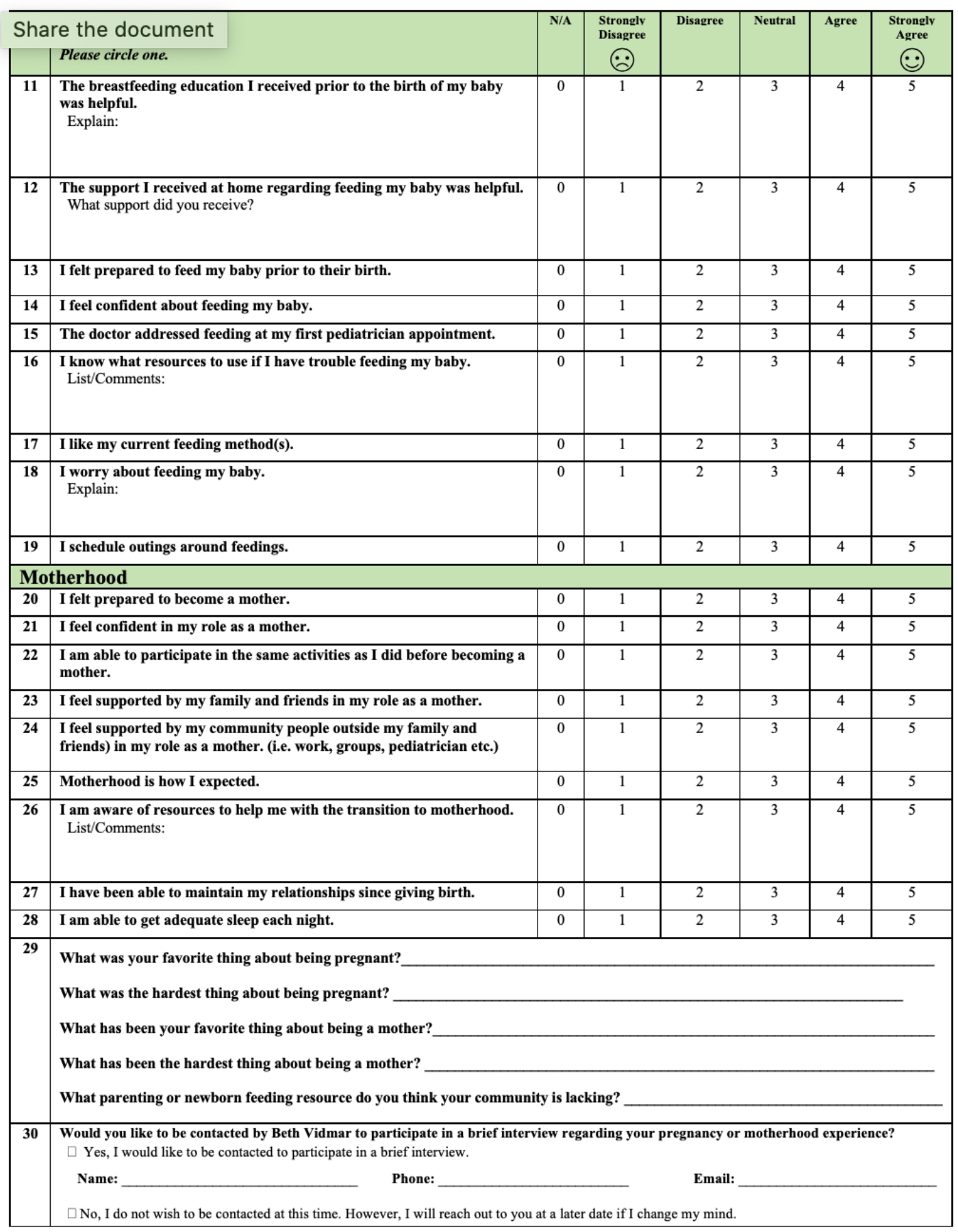




\author{
Appendix D \\ Interview Questions for Expectant Mother
}

\title{
Interview Questions-Expectant Mother
}

\section{Intro Script}

Hi my name is Beth Vidmar. I'm calling to thank you for participating in the needs assessment for mothers in Santa Barbara County and to ask if you have the time to answer some follow up questions now?

I am going to be asking you questions about motherhood, your relationships, and your pregnancy. If you would not like to share about any of the topics you can let me know. None of your answers will be associated with your name and I won't be contacting you again. Is ok to refer to some of your survey answers? I may repeat one or two of the questions in order to understand more about it. I'm going to be taking some note so excuse me if I pause.

Please feel free to stop me at any time if you need to go - I will try to keep it as brief as possible to respect your time.

\section{Infant Feeding}

Assess whether they received breastfeeding/infant feeding education yet.

- What made it helpful/unhelpful?

- Did you have questions that weren't made clear?

- Could anything have made it better? Bottle feeding classes?

- Do you feel pressured to feed a certain way? Where did the pressure come from?

- Do you feel like more support is needed before birth?

- Do you feel like you know resources available for after birth?

- Do you feel confident in how you will feed your baby? What made/makes you feel that confidence?

\section{Motherhood}

- What had been the hardest thing about this new transition to becoming a mother?

- How can they community better support you as a new mother? Classes or services

- How was/has your body been during pregnancy? Pelvic floor, back, joints? 
- Plans for taking leave and going back to work?

- Relationship and intimacy during pregnancy?

- Is there anything you would tell someone words of advice that you wish you'd have received for pregnancy or motherhood?

\section{Routines}

- Do you have a general routines set in place for yourself currently?

- Is there a part or time of routine that is more challenging than others now that you are pregnant?

- Do you plan to continue these routines after your baby is born?

- Is there anything else that I have not asked about has changed drastically since becoming pregnant?

\section{WEB Specific}

- Have you heard about WEB before? 


\author{
Appendix E \\ Interview Questions for Postpartum Mother \\ Interview Questions-Postpartum Mother
}

\title{
Intro Script
}

Hi my name is Beth Vidmar. I'm calling to thank you for participating in the needs assessment for mothers in Santa Barbara County and to ask if you have the time to answer some follow up questions now?

I am going to be asking you questions about motherhood, your relationships, and your baby. If you would not like to share about any of the topics you can absolutely let me know. None of your answers will be associated with your name and I won't be contacting you again. Is ok to refer to some of your survey answers? I may repeat one or two of the questions in order to understand more about it. I'm going to be taking some notes so excuse me if I pause,

Please feel free to stop me at any time if you need to go - I will try to keep it as brief as possible to respect your time.

\section{Infant Feeding}

Assess whether they received breastfeeding education prior to birth.

- What made it helpful/unhelpful?

- Did you have questions that weren't made clear?

- Could anything have made it better? Bottle feeding classes?

- Did you feel pressured to feed a certain way? Where did the pressure come from?

- Do you feel like more support is needed before birth, after birth, or feel adequate for both?

- Do you feel confident in feeding your baby? What made/makes you feel that confidence?

\section{Motherhood}

- What was the hardest thing about the transition to becoming a mother? How did this change if you had another child?

- How can they community better support you as a mother? Classes or services

- How was/has your body been recovery? Pelvic floor, back, joints?

- How has the transition back to work been? 
- How has your relationship transitioned and changed after giving birth? Intimacy and sex?

- Is there anything you would tell someone words of advice that you wish you'd have received before pregnancy?

\section{$\underline{\text { Routines }}$}

- Do you have a general routine set in place currently?

- Is there a part or time of routine that is more challenging than others?

- Did you plan these routines during pregnancy or did they naturally come after?

- Is there anything else that I have not asked about has changed drastically?

\section{WEB Specific}

- Why did/didn't you have WEB?

- If you had known about it would you have?

- In your opinion when is best time to have that visit?

- How would you have changed the visit? Relevant? Helpful? 


\section{Appendix F}

\section{Expectant Mother's Feelings on Infant Feeding}

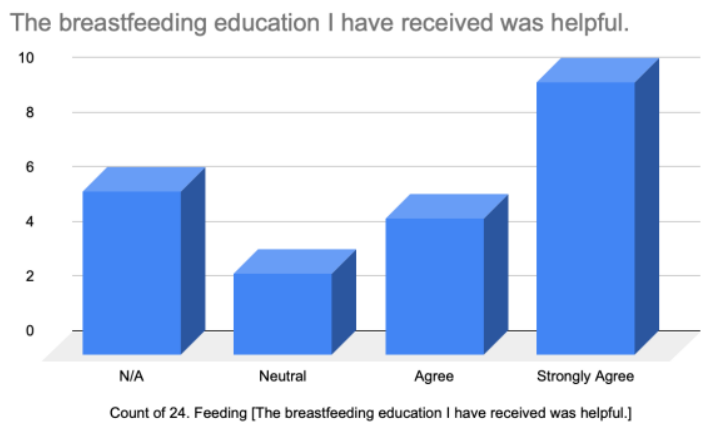

Figure 1.

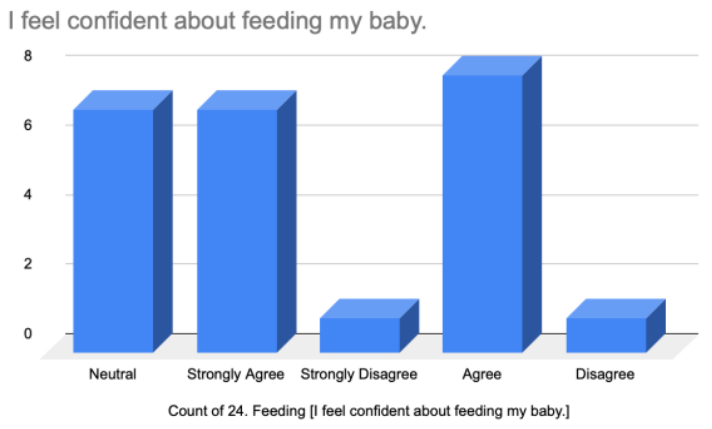

Figure 3.

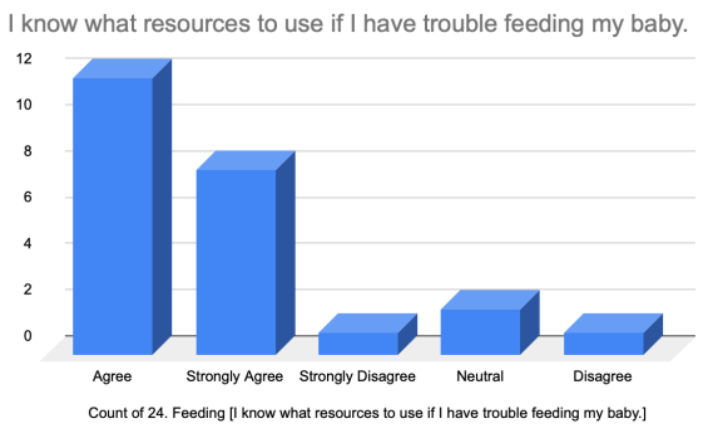

Figure 5.

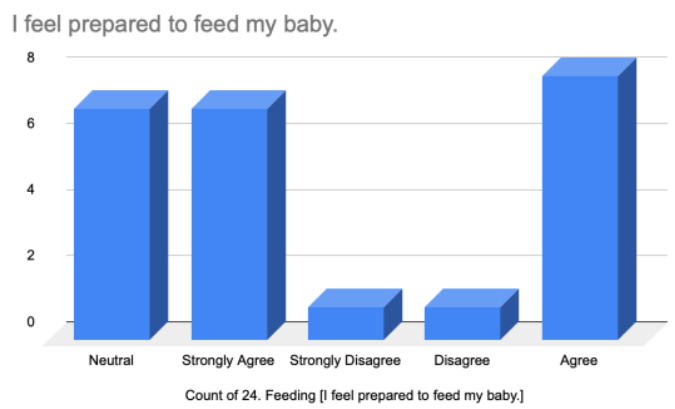

Figure 2.

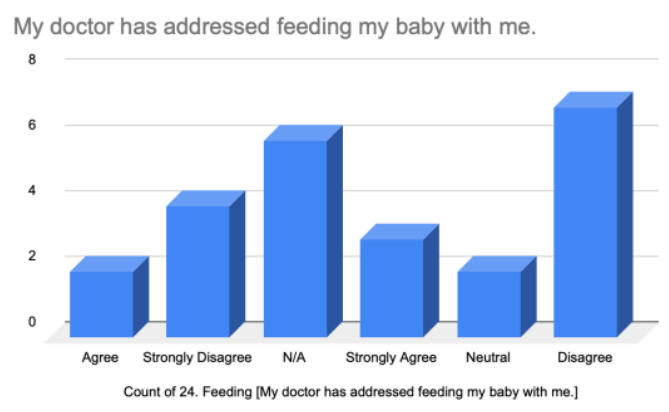

Figure 4.

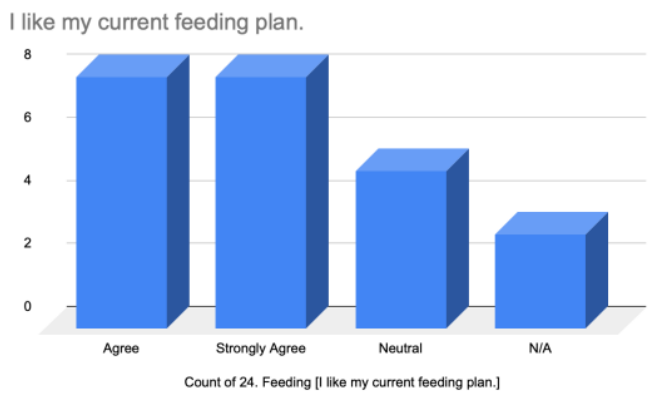

Figure 6. 


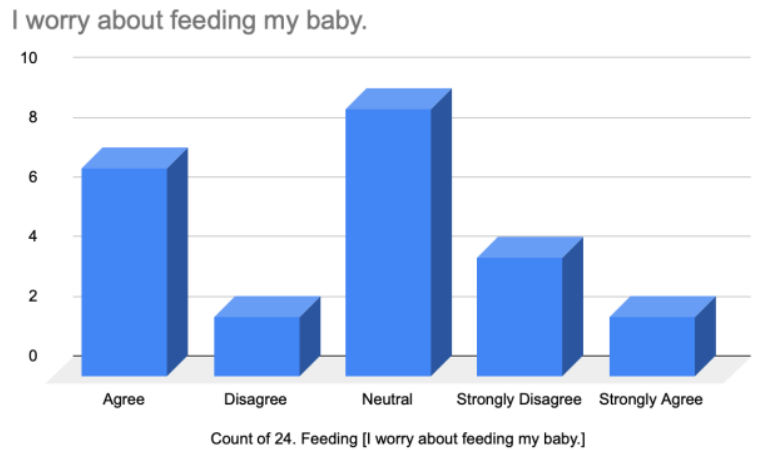




\section{Appendix G}

\section{Expectant Mother's Feelings on Motherhood}

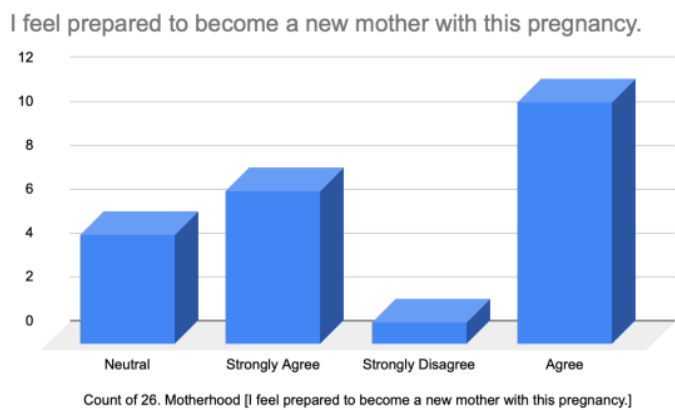

Figure 8.

I am able to participate in the same activities as I did before becoming pregnant.

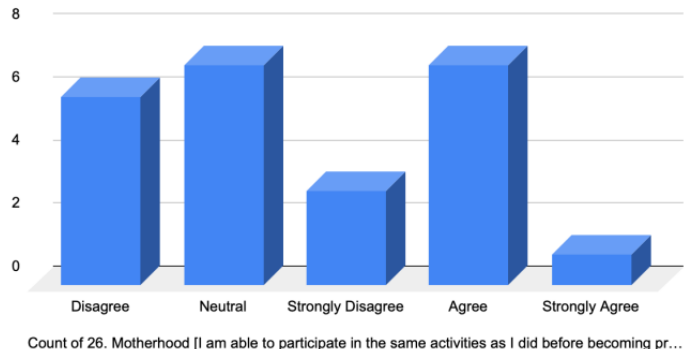

Figure 10.

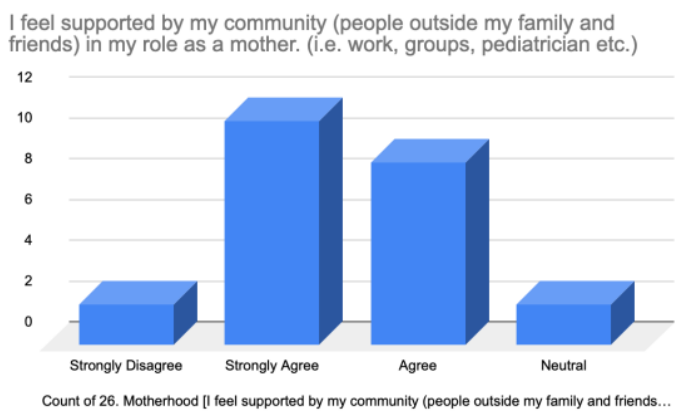

Figure 12.

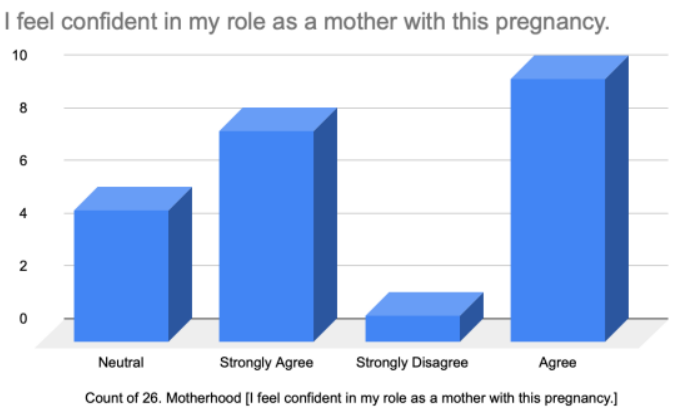

Figure 9.

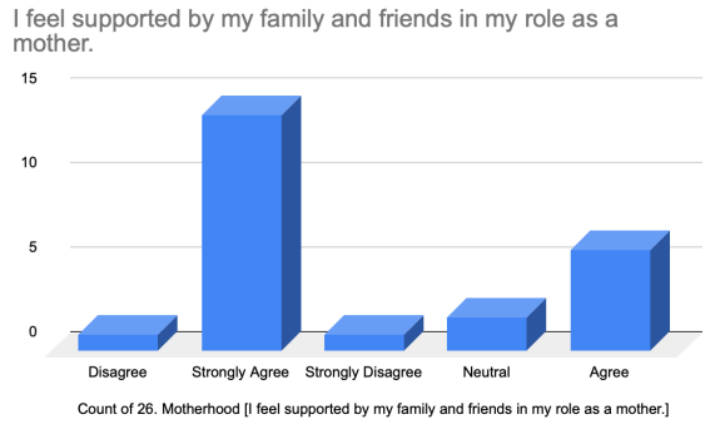

Figure 11.

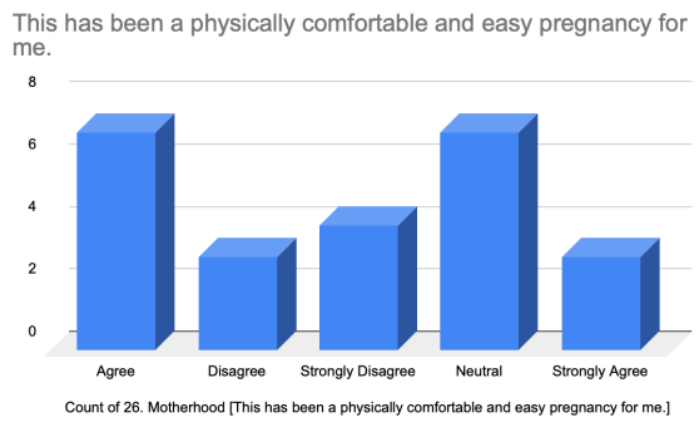

Figure 13. 


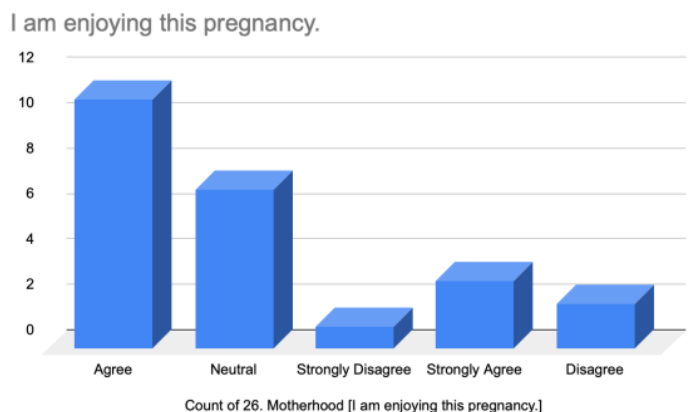

Figure 14.

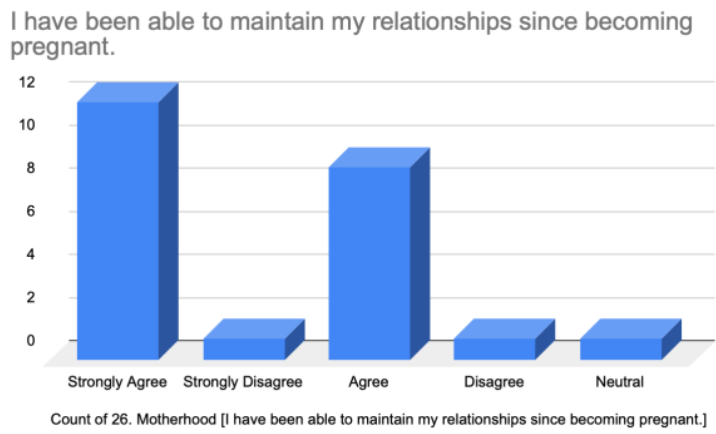

Figure 16.
I am aware of resources to help me with the transition to motherhood.

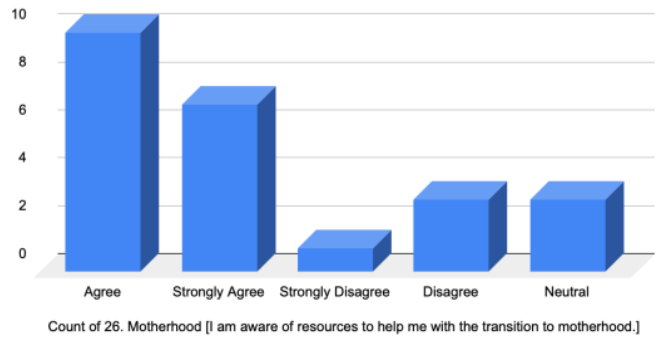

Figure 15.

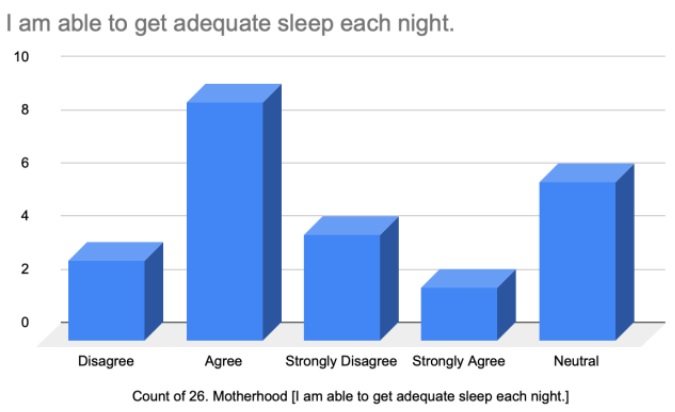

Figure 17. 


\section{Appendix $\mathrm{H}$}

Postpartum Mother's Feelings on Infant Feeding

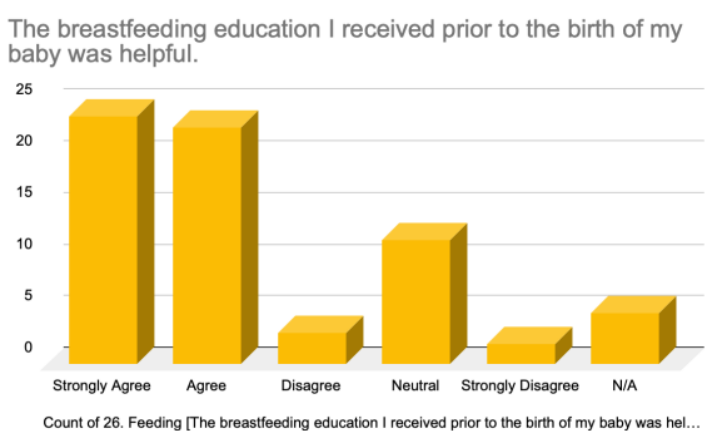

Figure 18.

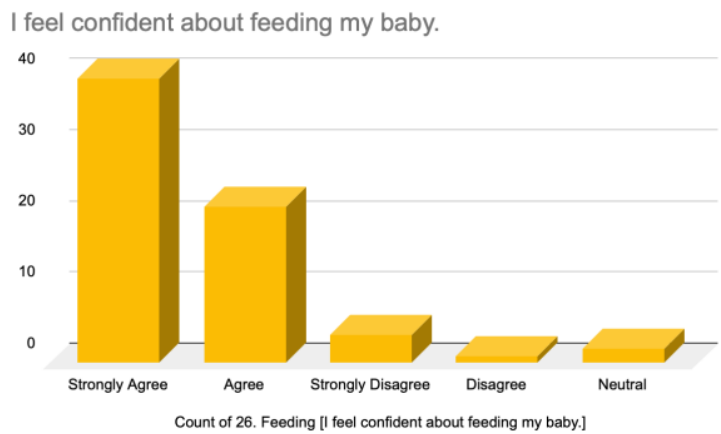

Figure 20.

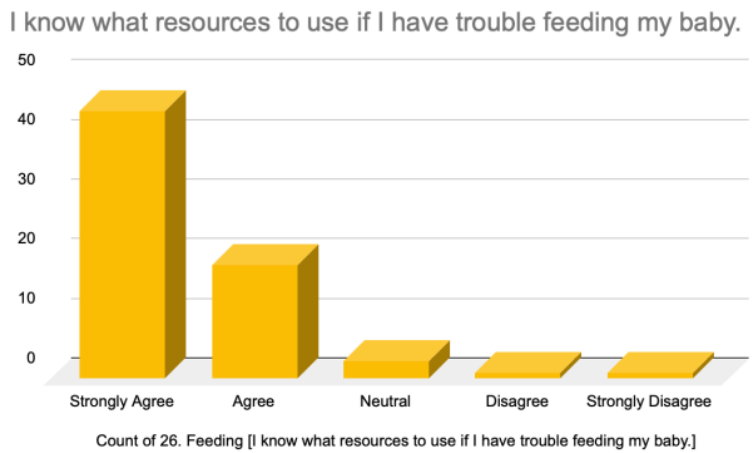

Figure 22.

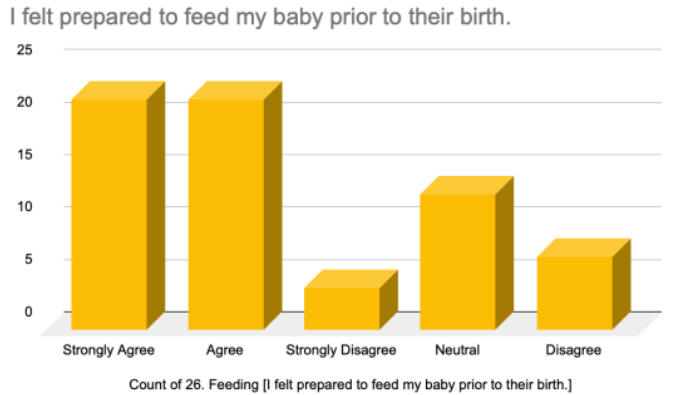

Figure 19.

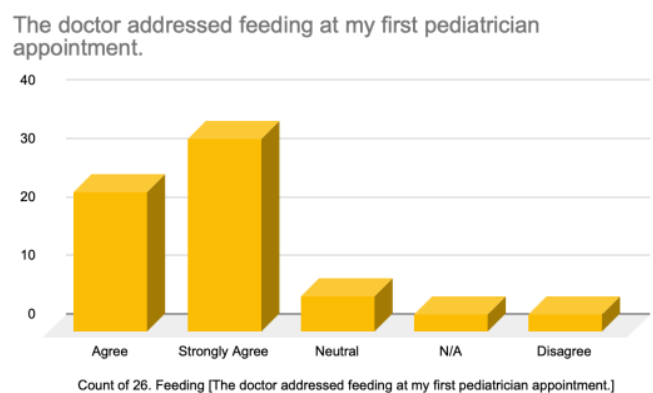

Figure 21.

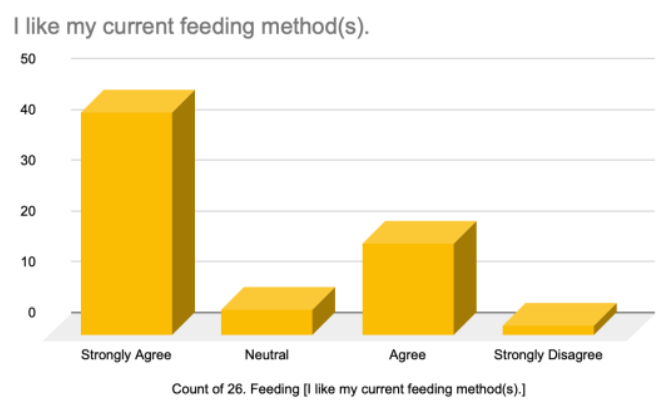

Figure 23. 


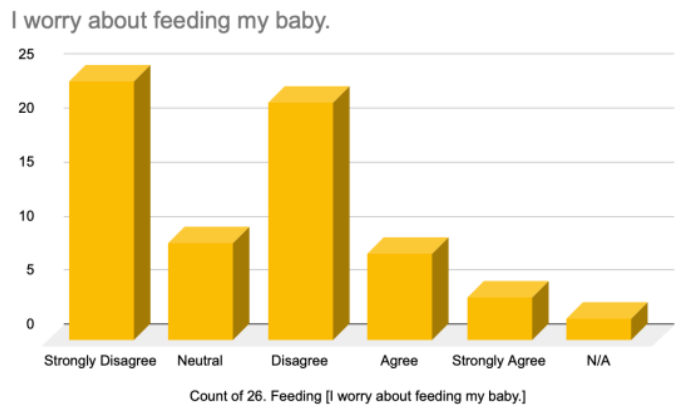

Figure 24.

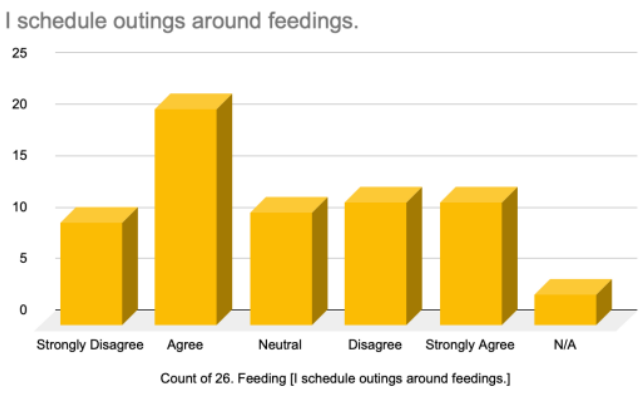

Figure 25. 


\section{Appendix I}

\section{Postpartum Mother's Feelings on Motherhood}

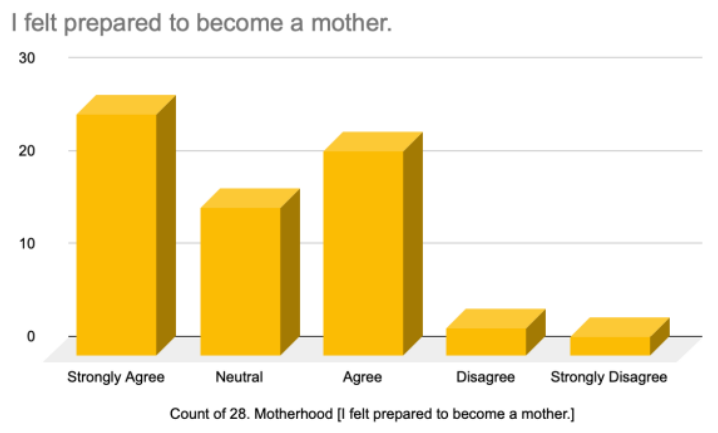

Figure 26.

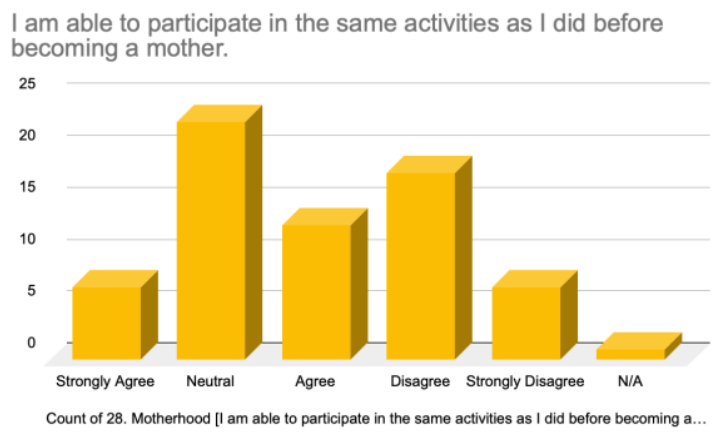

Figure 28.

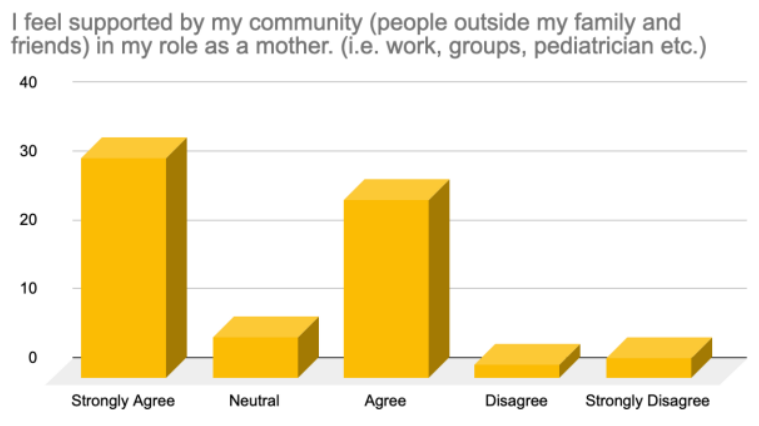

Count of 28. Motherhood [l feel supported by my community (people outside my family and friends...

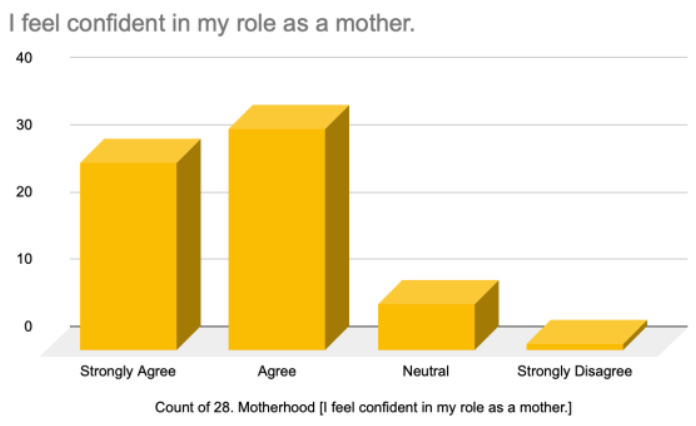

Figure 27.

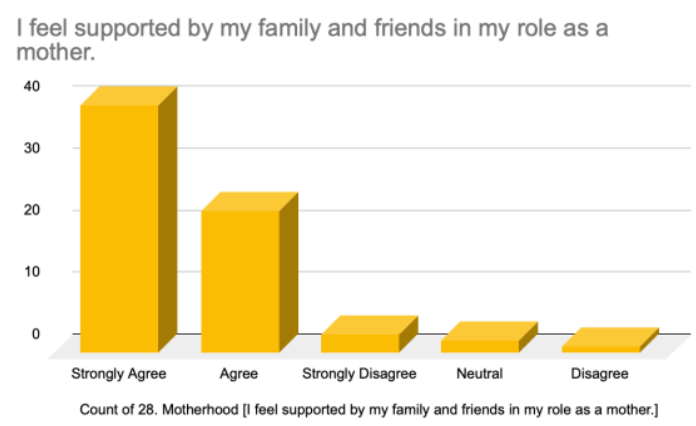

Figure 29.

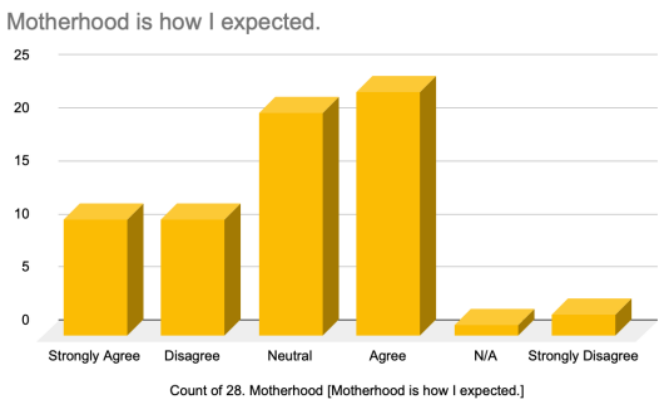


Figure 30.

I am aware of resources to help me with the transition to motherhood.

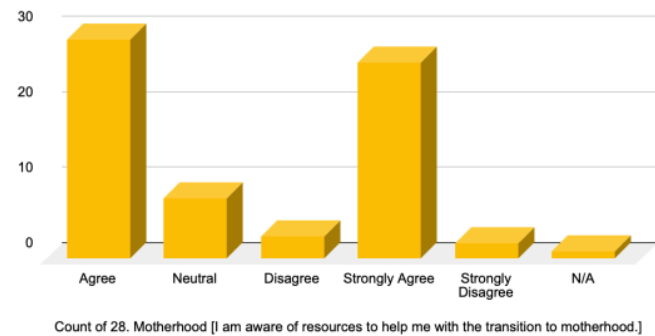

Figure 32.

I am able to get adequate sleep each night.

0

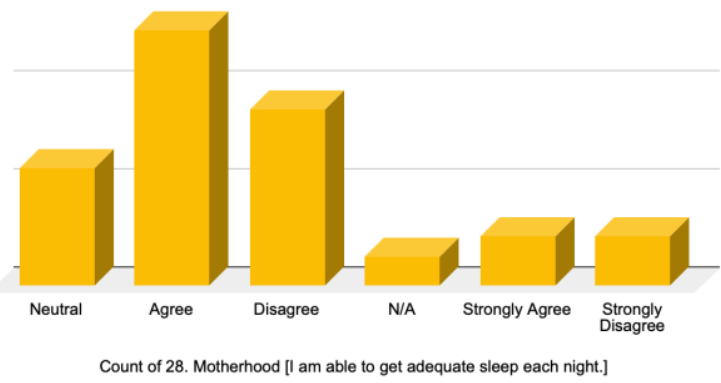

Figure 34.
Figure 31.

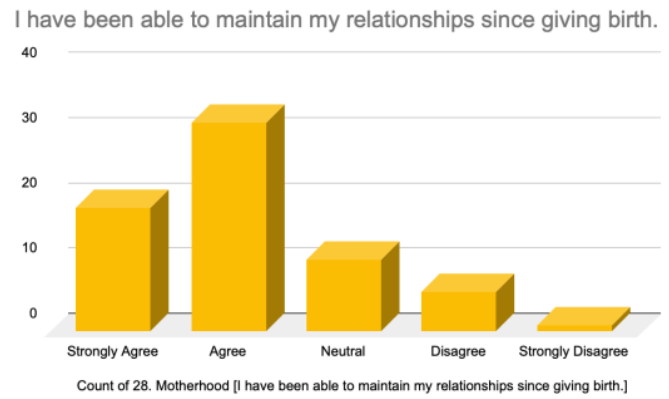

Figure 33. 


\section{Appendix J}

Results Deliverable

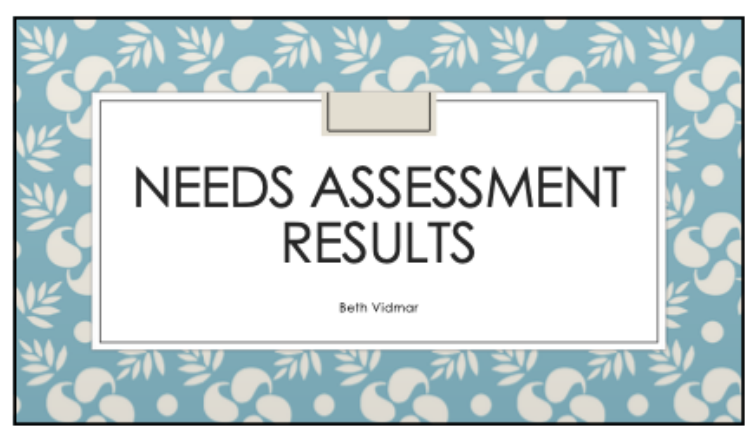

1

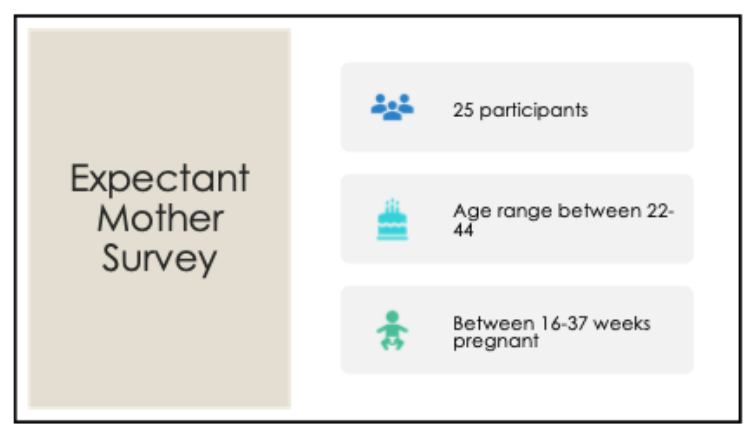

2

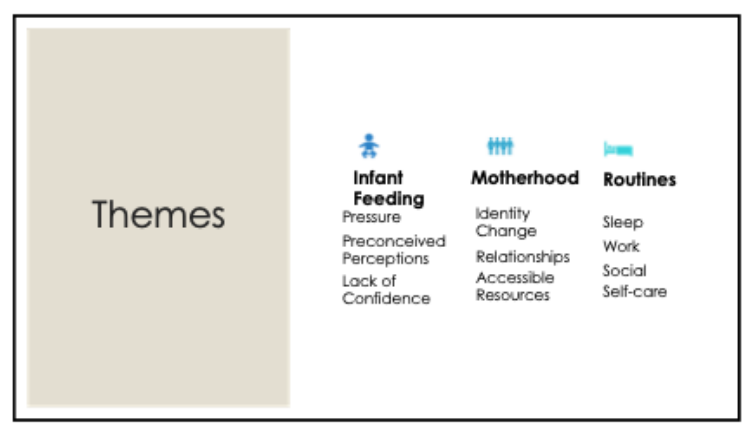

4

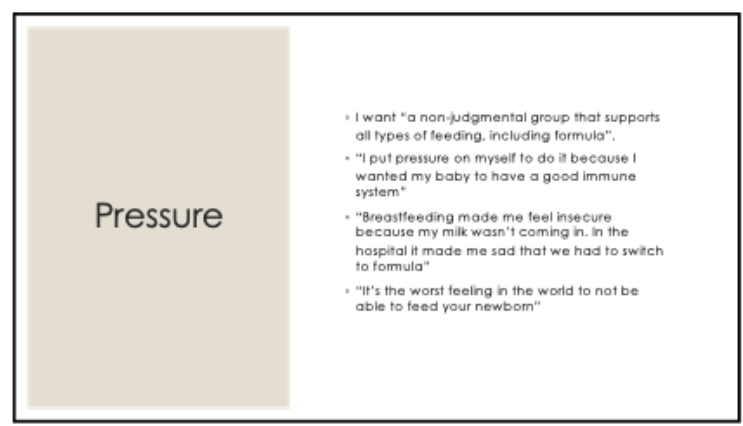

6 


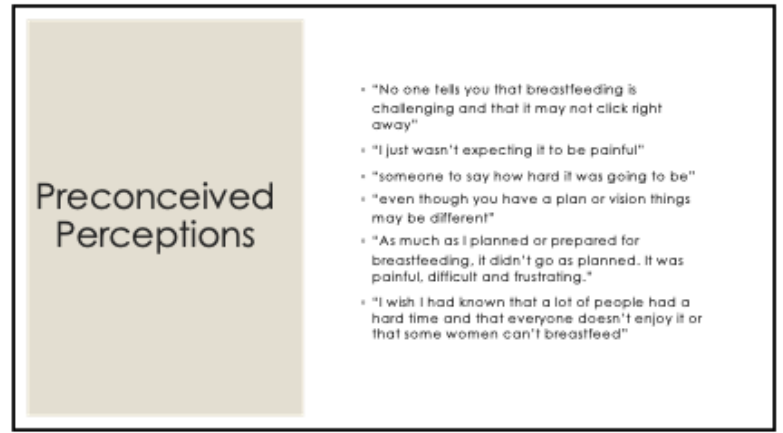

7

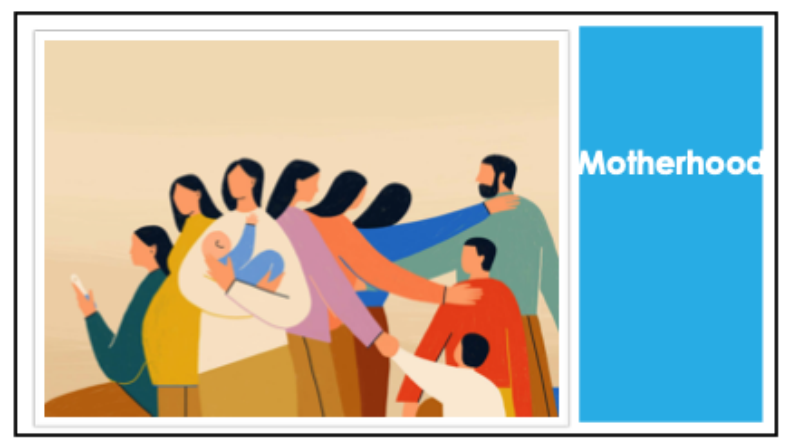

9

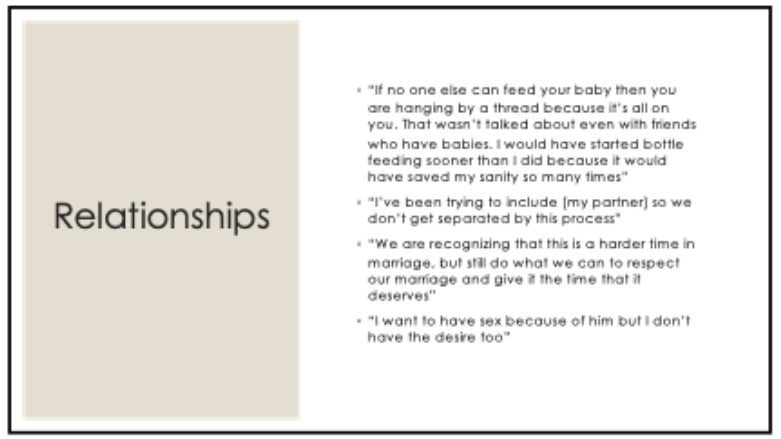

11

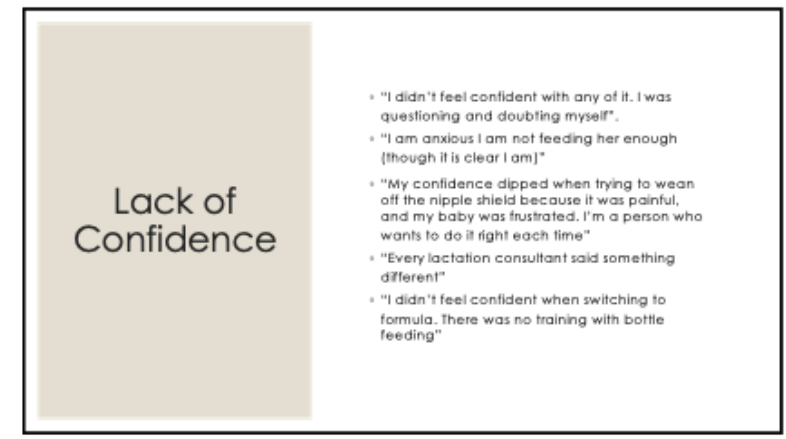

8

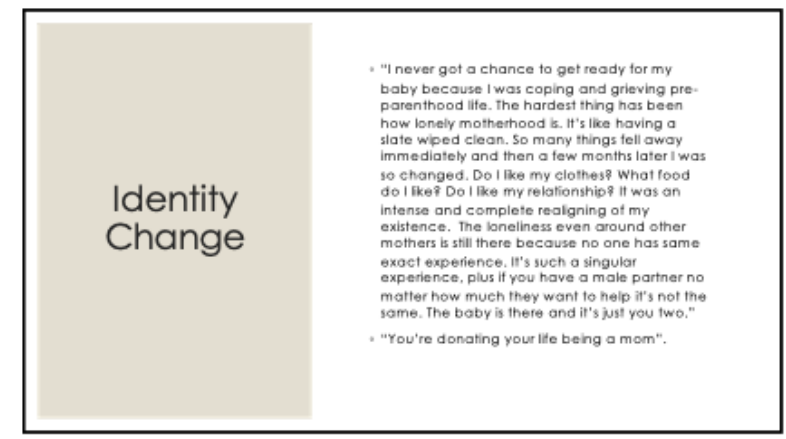

10

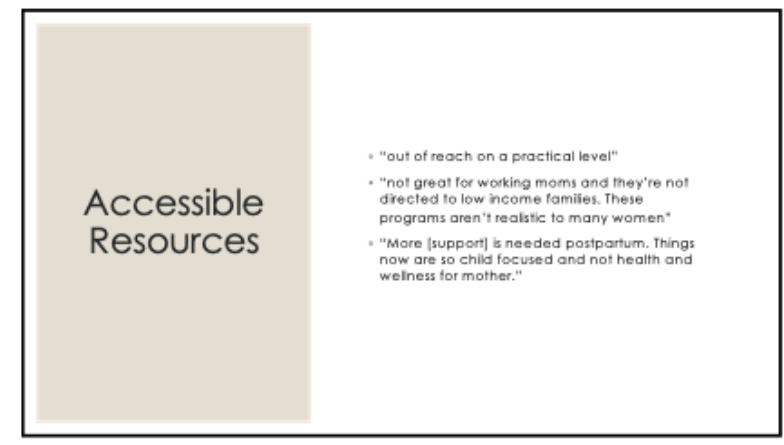

12 


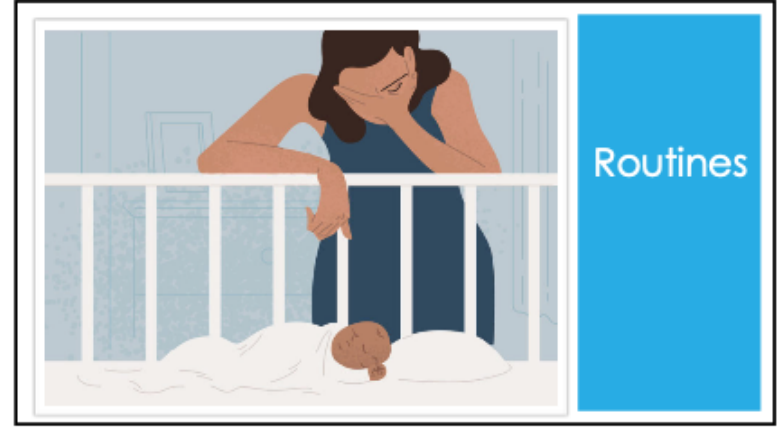

13

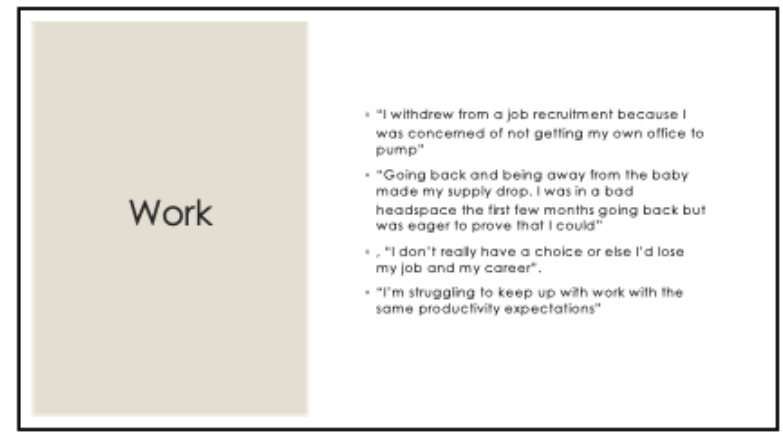

15

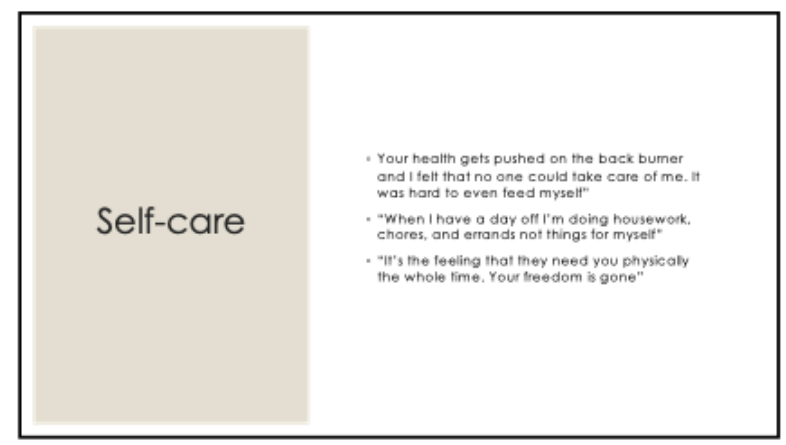

17

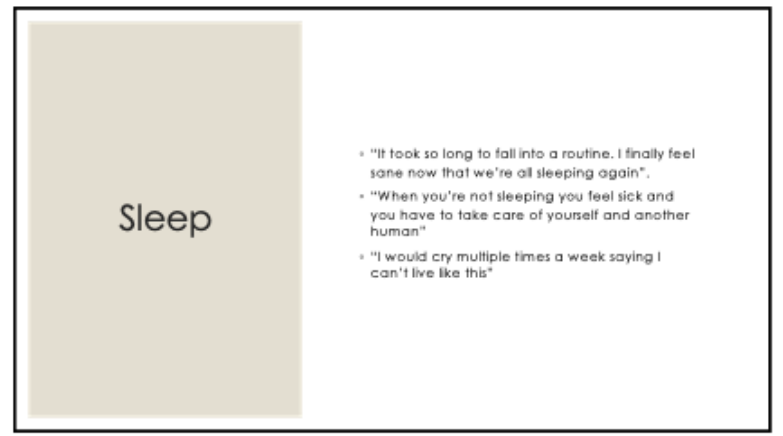

14

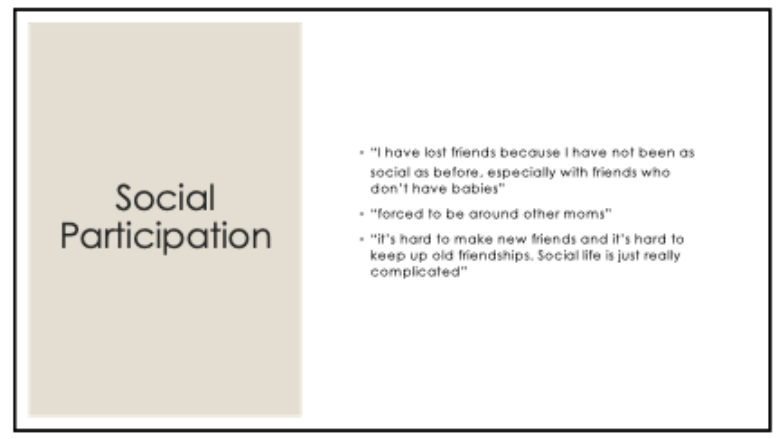

16

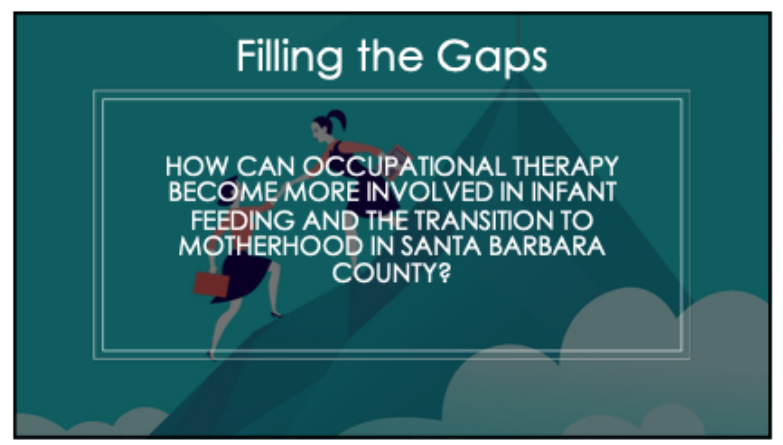




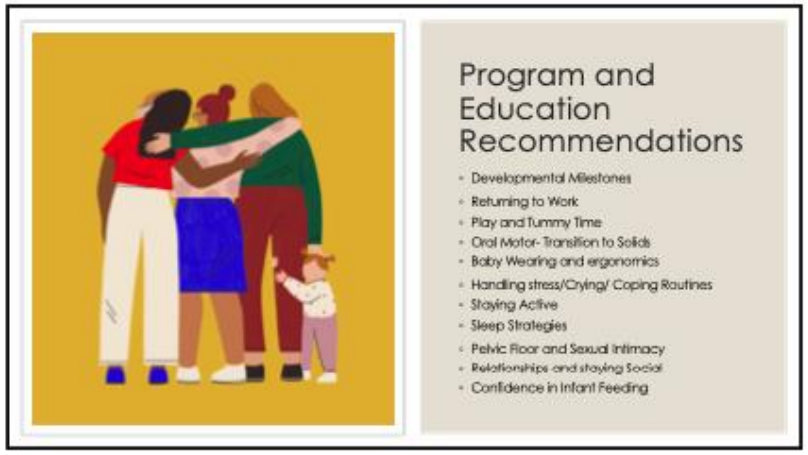

19 